\title{
EL USO DE APELATIVOS DIVINOS EN ÁMBITOS RURALES BÉTICOS
}

The Use of Divine Names in Rural Baetic Areas

JAIme Alvar EzQuerra

UNIVERSIDAD CARLOS III DE MADRID jalvar@hum.uc3m.es

Beatriz Pañeda Murcia

UniversidAd CARLOS III DE MADRID

bpaneda@hum.uc3m.es

\section{Abstract}

This paper analyses the divine onomastic sequences documented in the rural epigraphy of Baetica by applying the taxonomy of divine epithets developed within the EPIDI project. The aim is to determine whether or not the use of these onomastic formulae is independent of the usage found in the cities and, consequently, whether they reveal religious behaviours specific to the countryside that would allow us to speak of a rustic religious praxis, or whether, on the contrary, they reflect an orthopraxis determined by

\section{RESUMEN}

En este trabajo se analizan las secuencias onomásticas divinas documentadas por la epigrafía rural de la Bética mediante la aplicación de la taxonomía de epítetos divinos elaborada en el seno del proyecto EPIDI. Se pretende determinar si el uso de estas fórmulas onomásticas es o no independiente del que se constata en las ciudades $y$, por ende, si revelan comportamientos religiosos específicos del campo que nos permitan hablar de una praxis religiosa rústica, o si por el contrario reflejan una ortopraxis determinada 
urban religion. To this end, we conduct, firstly, a comparative study of the gods and epithets attested in the urban zones and in the rural areas of the province. Secondly, we examine the most singular deities and epithets from the rural milieu taking into account the circumstances that may have motivated the worshippers' choice of the deities and the divine appellatives concerned. por la religión urbana. Para ello, en primer lugar, se realiza un estudio comparativo de los dioses y de los epítetos atestiguados en los núcleos urbanos y en las zonas rurales de la provincia. En segundo lugar, se examinan las deidades y los epítetos rurales más llamativos, atendiendo a las circunstancias que pudieron haber motivado la elección de las deidades y de los apelativos divinos en cuestión.

\section{KeYWORDS}

Baetica; Divine epithets; Roman religion; Rural world; Votive epigraphy.

\section{Palabras Clave}

Bética; Epigrafía votiva; Epítetos divinos; Mundo rural; Religión romana. 
La PRopuesta temática del DeCimoctavo coloquio de la Asociación Arys nos ha servido de inspiración para participar con un estudio vinculado al proyecto de investigación Epitetos divinos: experiencia religiosa y relaciones de poder en Hispania, que venimos desarrollando durante los tres últimos años en la Universidad Carlos III de Madrid. ${ }^{1}$ Entre los resultados logrados hasta el momento por nuestro equipo de investigación podemos mencionar no solo una base de datos que recoge todos los epítetos divinos constatados por la epigrafía peninsular, sino también un complejo cuadro taxonómico que presentaremos próximamente, como propuesta conjunta de los miembros del proyecto, y que nos sirve como guía para la catalogación de los epítetos estudiados en este trabajo.

Estas son las dos coordenadas sobre las que se construye el presente estudio sobre los usos de los apelativos divinos en entornos rurales de la Bética, así como los trabajos de José Carlos López y Alejandro Beltrán en este volumen. ${ }^{2}$ En efecto, la confluencia de intereses entre el proyecto EPIDI y la problemática del coloquio nos ha llevado a analizar las tres provincias de la Hispania romana desde la perspectiva EPIDI. Así pues, de entre todas las vías de acceso a la praxis religiosa, nos hemos centrado en las secuencias onomásticas empleadas para nombrar a los dioses en la epigrafía de ámbito rural con el fin de determinar si su uso es o no independiente del que se constata en las ciudades. Pretendemos, por tanto, observar si la onomástica divina rural refleja peculiaridades religiosas derivadas del ámbito socioeconómico en el que se desarrolla la acción ritual de los devotos. No obstante, somos conscientes

1. Este trabajo es resultado del proyecto de investigación EPIDI, Epítetos divinos: experiencia religiosa $y$ relaciones de poder en Hispania (HAR2017-84789-C2-2-P), financiado por el Ministerio de Ciencia e Innovación.

2. Infra, pp. 209-237 y 239-269. 
de las limitaciones que imponen a nuestra pesquisa la escasez y la mediocridad de las inscripciones halladas en el campo y, en consecuencia, tenemos presente que el propio parámetro elegido a partir de nuestro proyecto de investigación, los epítetos, puede no resultar operativo para el propósito del XVIII congreso Arys: la identificación de las peculiaridades religiosas rurales.

Para la realización de este trabajo, hemos recopilado toda la epigrafía religiosa de la Bética y hemos prestado especial atención a las inscripciones que presentan epíteto o atributo onomástico. A continuación, hemos clasificado los epítetos de acuerdo a la taxonomía desarrollada en el marco del proyecto EPIDI, y hemos hecho un estudio comparativo de los dioses y de los epítetos atestiguados en los núcleos urbanos y en las zonas rurales. En las páginas que siguen presentaremos, en primer lugar, una comparativa entre las divinidades y las clases de atributos onomásticos documentados en dichas dos áreas. En segundo lugar, analizaremos los casos rurales más llamativos, atendiendo a las causas que pudieron haber motivado la elección de las deidades y de las secuencias onomásticas atestiguadas, siempre teniendo en cuenta la condición socio-económica de los devotos y sus relaciones con el ámbito urbano.

\section{LA DOCUMENTACión EN CIFRAS: DIOSES Y EPÍTETOS EN LA BÉTICA URBANA Y RURAL}

Según la base de datos de Clauss-Slaby (EDCS), la epigrafía bética ha proporcionado 382 inscripciones de contenido religioso, incluidas todas aquellas concernientes al culto imperial. Si eliminamos las que no mencionan una divinidad y las que se refieren a un emperador divinizado, quedarían unas 300 . De ellas, el $74 \%$ contiene epítetos divinos, frente a un $26 \%$ que presenta únicamente teónimos. Del total de 300 tan solo podemos computar con una relativa certeza 50 epígrafes procedentes de ámbitos extraurbanos, lo que supone un $16 \%$ del total. A su vez, una veintena no presenta epíteto, mientras que la treintena restante registra una variedad de 38 atributos.

En total, las 50 inscripciones del ámbito rural bético atestiguan 26 o 27 divinidades distintas, invocadas con o sin epíteto. En ocho ocasiones está documentado Júpiter, en cinco de ellas como Óptimo Máximo, mientras que Hércules, Mercurio, Ceres y Salus aparecen tres veces, al igual que los Lares, pero estos son en una ocasión Viales y en otra Augusti. Silvano aparece en dos inscripciones y el numen Silvani en una. También Minerva e Isis están atestiguadas por dos documentos cada una. En una ocasión se menciona a Juno, Diana, Marte, Venus, Liber Pater (junto a una segunda dudosa), Epona, Ataecina, Domina Sancta (identificada por algunos autores 
con Ataecina), Proserpina, Betatun, Dea Medica, Stata Mater, Fama Augusta, Luna, Genius municipii, Arbor Sancta y las ninfas augustas ${ }^{3}$.

De acuerdo con la clasificación taxonómica establecida en el marco del proyecto EPIDI, la diversidad de epítetos atribuidos a estas divinidades se distribuyen de la siguiente manera ${ }^{4}$ (Fig. 1): el 30,6\% de los epítetos cultuales se enmarca en la tipología denominada "operacionales institucionales", y en concreto, en la subcategoría "epítetos de poder", que en la Bética rural está constituida únicamente por los apelativos Augustus/a y Dominus/a. Le sigue un 27,8\% de epítetos cualitativos inherentes sustanciales, es decir, que expresan una cualidad inherente a los entes divinos, entre los cuales Deus y Sanctus son dominantes. Un 16,7\% son epítetos cualitativos relacionales jerárquicos de superioridad, esto es, calificativos cuyo fin es resaltar una característica de un dios en relación o en comparación con el resto de divinidades. En este caso, todos los testimonios salvo uno se corresponden con la designación de Júpiter como Optimus Maximus; la excepción es una dedicación a Isis Panthea. El 8,3\% son epítetos toponímicos, resultantes de actos de devoción dirigidos al genius de un municipium determinado, a Júpiter Óptimo Máximo Capitolino o a la diosa Ataecina Turibrigensis. El resto son topográficos relativos a realidades tangibles, como una dedicatoria a los Lares Viales, o intangibles, como es la invocación a un Mercurio Supernus, y operacionales de varios tipos, como por ejemplo Dea Medica, ligado al cuidado de la salud, o Stata Mater, la "Madre que Paraliza", en relación con la detención de incendios.

Los devotos, por su parte, son mayoritariamente ingenui con tria nomina, aunque también encontramos ciudadanos romanos, libertos y esclavos, y en tan solo una ocasión

3. Se omiten en este momento todas las referencias bibliográficas, pues serán citadas en las páginas siguientes. No se retiene como documento válido para nuestro estudio el miliario: Ti(berius) Caesar divi / Augusti f(ilius) di/vi Iuli nepos / Augustus pontifex max(imus) XXI co(n)s(ul) V imp(erator) / VIII tr(ibunicia) potest(ate) XXXVII / ab Iano Augusto / [et] Baetem(!) usque / ad Oceanum / LXXVIII (AE 1912, 11 = HEpOL 541), pues se trata del topónimo indicativo del límite de la Bética. Es posible que en el lugar indicado por el miliario se realizara algún gesto devocional, pero sería inapropiado considerarlo documento acreditativo de culto rural a Jano. En el año 2018 se descubrió en el término municipal de Mengíbar (Jaén) una estructura arrasada que se ha pretendido identificar con el Jano Augusto de nuestra inscripción, con el que se monumentalizaba el límite entre la Tarraconense y Bética en la vía Augusta (https://historia.nationalgeographic.com.es/a/descubierto-jano-augusto-puerta-entrada-a-provinciaromana-betica_12747/3). Sin embargo, no hay seguridad de que lo hallado sea un arco, ni de que se corresponda con la localización propuesta. La discusión puede seguirse parcialmente en https://terraeantiqvae.com/group/hispaniaromana/forum/topics/localizado-en-mengibar-jaen-el-arco-de-janoel-cual-marcaba-la-en), con la crítica posición de la Dra. Alicia Canto.

4. Para una breve definición de las principales categorías de epítetos, véase J.C. López Gómez en este mismo volumen, pp. 209-237. 
registramos una dedicatoria sufragada por un collegium. En las zonas urbanas se constata un orden de prioridad similar de los estatus socio-jurídicos de los dedicantes y, como en el campo, una clara primacía del género masculino sobre el femenino (Fig. 2).

Asimismo, las categorías de epítetos atestiguadas en ámbito rural y urbano son semejantes, al igual que lo es el orden jerárquico existente entre ellas, aunque las relaciones de proporcionalidad varían de un dominio territorial al otro. En efecto, en la ciudad se observa una amplia diferencia entre la clase dominante, epítetos de poder, y el segundo grupo, epítetos toponímicos, lo que contrasta con la casi equiparación de ambas categorías en el campo. La razón de tal discrepancia es el frecuente uso en el entorno urbano del apelativo Augustus/a, que representa el $80 \%$ de los testimonios de epítetos de poder. En segundo lugar, le sigue Dominus/a, relativamente frecuente, y por último Regina (solo en femenino). Los epítetos toponímicos corresponden, salvo excepción, a la secuencia Genius + municipii/coloniae/ oppidi. Deus/a es el epíteto cualitativo inherente dominante, mientras que entre los atributos cualitativos relacionales jerárquicos prima con creces Optimus Maximus, de Júpiter, al que sigue de lejos Pantheus. Los apelativos bélicos son Victor/Victrix e Invictus/a y el resto de categorías están formadas por ejemplos singulares (Fig. 3).

La epigrafía de la Bética urbana, dada su abundancia, atestigua una mayor diversidad de divinidades que la de la Bética rural (hasta 65), pero estas son en gran medida coincidentes con las constatadas en el campo. En efecto, Hércules, Mercurio, Ceres, Salus, Silvano, Minerva, Isis, Juno, Diana, Marte, Venus, Liber Pater, los Genii municipii y los Lares Augusti o Augustales, venerados en el campo, aparecen con mayor o menor frecuencia en las ciudades. Ahora bien, el número de documentos relativos a cada divinidad varía de un ámbito al otro (Fig. 4). Los Genii de comunidades cívicas (oppida, municipia, coloniae) son la figura divina mejor atestiguada en el entorno urbano. Tras ellos se sitúa Júpiter, el dios dominante en el campo, principalmente bajo su forma de Júpiter Óptimo Máximo. Le suceden Hércules, Marte, Venus, Victoria (Augusta), Isis y, con igual número de testimonios, Fortuna, Mercurio y Minerva, además de muchas otras deidades con menor representación, la mayoría de las cuales documentadas en el campo. No obstante, otros dioses presentes en entornos rurales revisten un carácter singular, bien porque hasta el momento no se han documentado en los núcleos urbanos, bien porque constituyen un unicum en la epigrafía provincial. En ellos centraremos nuestra atención en el siguiente apartado con el fin de determinar si están o no ligados a una praxis religiosa rústica, entendida esta según la definición de "rústico" ofrecida en la introducción de este volumen. 


\section{Dioses De CARÁCTER SINGULAR}

De las 27 entidades divinas constatadas en el ámbito rural bético, la más singular es Betatun, pues se trata de una de las dos únicas divinidades ibéricas de teónimo conocido en la Bética, y la cuarta en toda la Península. ${ }^{5}$ Está atestiguada por una inscripción votiva procedente de Fuerte del Rey, en Jaén (Fig. 5):

Betatun / Aelia •Belesi (scil. filia?) • ar (am scil. posuit) / sorte • ius $(s) u / v($ otum $) \bullet s($ olvit $)$ - $l$ (ibens) $\bullet$ m(erito) ${ }^{6}$

El hecho de que esté documentada en un entorno rural es especialmente significativo, ya que sugiere una práctica religiosa diferente a la de las áreas urbanas, en las que no se ha confirmado la advocación de una divinidad local. ${ }^{7}$ La acción ritual conmemorada por la inscripción parece haberse llevado a cabo en lo que pudo haber sido un santuario, según se desprende de los exiguos y fortuitos restos arqueológicos, de presunto carácter oracular si concedemos una centralidad paradigmática al término sorte. Añádase a esa constatación el hecho de que las letras de la última línea V.S.L.M son las más grandes de todo el texto, incluso mayores que las del dios, lo que sin duda es un detalle que expresa una estrategia de comunicación con la divinidad invocada conscientemente elegida por la donante. Es cierto que, al tratarse de un unicum, cualquier inferencia puede resultar excesiva. Pero a favor de una praxis religiosa diferencial juega también el nombre de la dedicante, una mujer de onomástica híbrida, Aelia Belesi o Belesiar. ${ }^{8}$ Ahora bien, si la coherencia de una devota de estirpe local que venera a una divinidad prerromana en ámbito rural parece indiscutible, lo cierto es que la persona se expresa en latín, utilizando no solo un soporte lingüístico ajeno a su tradición ancestral con formulación ritual típicamente latina, sino también un soporte cultural en ella innovador, la epigrafía. La conclusión que de ello se

5. Otras divinidades ibéricas de teónimo conocido son Deus Seitundus, a quien fue dedicado un altar votivo en Susqueda, Gerona $(A E$ 1985, $633=A E 2016,897=H E p O L$ 12863), Salagin, conocido por una inscripción recientemente descubierta en Riotinto (Gimeno y Velaza, 2021), y posiblemente Salaecus, conocido por una inscripción votiva del área minera de Carthago Nova (AE 2010, 754; HEpOL 27132).

6. HEpOL 25969; Corzo Pérez et al., 2007; Orduña Aznar, 2009.

7. Como señala Beltrán Ortega en este mismo volumen, pp. 239-269, en la provincia de Lusitania las divinidades de origen local están mucho más presentes en los entornos rurales que en los centros urbanos, pero también aparecen en estos últimos.

8. Hay incertidumbre sobre el nombre exacto. Los primeros editores del epígrafe leyeron Belesi, separado mediante una dudosa interpunción de ar, que suponen corresponder a $\operatorname{ar}(a m)$, mientras que Orduña Aznar, 2009, propone un convincente nombre personal Belesiar. 
extrae es que la aparente discontinuidad de la praxis cultual en ámbito rural puede ser un fenómeno casual, pues nada extrañaría que ese mismo epígrafe u otro similar hubiera aparecido en ámbito urbano. Ahora bien, se asume para el monumento una cronología comprendida de forma imprecisa entre la segunda mitad del siglo I a.C. y mediados del I d.C.; los argumentos no son convincentes, ni siquiera el de la grafía iusu. Nuestra impresión es que ha operado un mecanismo acomodaticio entre los estudiosos, pues las anomalías gráficas y gramaticales se dan en cualquier tiempo y ocasión. Al hallarnos aquí ante uno de los escasos teónimos ibéricos documentados epigráficamente, se ha forzado una cronología tardorrepublicana o julio-claudia para evitar que este hallazgo altere significativamente la ejemplaridad de la Bética como provincia precozmente romanizada e incluso transculturada, como se pone de manifiesto por la pérdida de los dioses ancestrales en beneficio de los romanos. En consecuencia, una alta cronología, contraria a la práctica habitual de llevar toda la epigrafía sin datación al siglo II d.C., permitiría postular que este sería un testimonio tardío del proceso de transformación de las prácticas religiosas prerromanas. Es, por tanto, un hito en un itinerario que no solo va integrando progresivamente a la población local en la ortopraxis religiosa romana, sino que también la adapta, en paralelo, al nuevo discurso ideológico y ritual propio de la romanitas. Sin embargo, la onomástica de la donante nos hace pensar más bien en una cronología adrianea. De hecho, situar el documento siglo y medio después del proceso de conquista no alivia significativamente el problema del proceso de integración cultural. No se oculta, por tanto, la magnitud de las dificultades que supone la presencia de cultos de deidades prerromanas en pleno período imperial, pero no debemos enmascarar la realidad con soluciones inconsistentes.

Otra deidad insólita es Stata Mater, que aparece en la inscripción de una basa de estatua hallada en un lugar incierto de una propiedad rústica a unos $4 \mathrm{~km}$ de Granada, en la Casería Titos. ${ }^{9}$ A partir del texto epigráfico sabemos que un dunviro de Ilurco ${ }^{10} \mathrm{P}$. Cornelio Gálico, hizo la donación a sus expensas de una estatua de Stata Mater con todos sus ornamentos, que colocó sobre una basa en la que inscribió el

9. CIL II²/5, $670=I L P G r a n a d a 60=H E p O L$ 2770: $P($ ublius $)$ Cornelius $P($ ubli $) f($ ilius $) /$ Quirina Gallicus II/vir Ilurconensis / Statam Matrem / cum suis ornamentis / d(e)s(ua) p(ecunia) d(edit)d(edicavit). Cf. Sotomayor Muro, 1966, p. 354, lám. XCI; Pastor y Mendoza Eguaras, 1987, pp. 123-125, n 60; Pastor Muñoz, 1987-1988, pp. 237-250; Pastor Muñoz, 2002, pp. 88-89, fig. 38, a-b.

10. Se trata de un oppidum bastetano con niveles altoimperiales. Plinio lo menciona en Plin., N.H. III 10. Está situado en el Cerro de los Infantes, término municipal de Pinos Puente (Granada), en la zona septentrional de la Vega de Granada. No sabemos en qué momento alcanzó el estatuto de municipio. Cf. Adroher Auroux, López Marcos y Pachón Romero, 2002, pp. 146-147. 
texto conmemorativo que nos ha llegado. ${ }^{11}$ Esa devota acción se realizó en un momento indeterminado del siglo II d.C. Stata Mater, la "Madre que Detiene/Paraliza", es una deidad compital que tenía una estatua en el Foro de Roma hasta comienzos del siglo I a.C., ${ }^{12}$ desde donde, según Festo, se difundiría hacia los vici, es decir, los barrios de la ciudad. ${ }^{13}$ No podemos establecer las razones que pudo haber tenido Gálico para una expresión religiosa de esa naturaleza. Stata Mater era invocada específicamente para evitar incendios ${ }^{14}$; de hecho, es una deidad asociada a Vulcano. ${ }^{15}$ En Roma, su intervención protectora se asocia a la gestión de los vicomagistri, presidentes de las asociaciones vecinales $^{16} \mathrm{y}$, a partir de la época de Augusto, se le atribuye el epíteto de Augusta, ${ }^{17}$ aunque ese no es nuestro caso. En una inscripción se establece su conexión con Fortuna mediante la cadena onomástica Fortuna Augusta Stata. ${ }^{18}$ Pudiera ser que la atribución de una capacidad específica del control de los incendios se hubiera transferido progre-

11. Cum suis ornamentis podría entenderse como los aditamentos necesarios para un sacellum o un fanum; sin embargo, también puede referirse a los ornamentos de la estatua, como se confirma en casos como el de Diana en San Roque, Cádiz (HEpOL 574): Dianae Aug(ustae) / Fabia C(ai) f(ilia) Fabiana cum ornamen/tis i(nfra) s(criptis) epulo dato d(at)d(edicat) // catella cum cylindr(i)s n(umero) VII armillas cum cy/lindris XX antemanus cum cylindris n(umero) XIII peris/celia cum cylindris n(umero) XVIII / anulos gemmatos n(umero) II. Igualmente testimonial es la basa de estatua procedente de Acci (Guadix, Granada) dedicada a Isis por una pariente de la que dedicó a Diana la estatua anterior, ambas pertenecientes a la acaudalada familia de los Fabii Fabiani (HEpOL 9489): Isidi · Puel[lae] / iussu · dei · Net[onis?] / Fabia · L(uci)

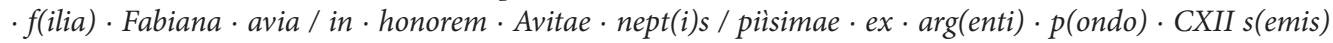
(unciarum) (semunciae) (scrupulorum) V/ item - ornamenta $\cdot$ in basilio unio et $\cdot$ margarita / $n$ (umero) $\cdot V I$ - zmaragdi $\cdot$ duo $\cdot$ cylindri $\cdot n(u m e r o) \cdot V I I \cdot$ gemma $\cdot$ car/bunclus gemma $\cdot$ hyacinthus gemmae $\cdot$ cerauniae I duae $\cdot$ in auribus $\cdot$ zmaragdi $\cdot$ duo $\cdot$ margarita $\cdot$ duo / in collo $\cdot$ quadribacium $\cdot$ margarita $\cdot n$ (umero) XXXVI . / zmaragdis $\cdot n$ (umero) $\cdot$ XVIII $\cdot$ in clusuris $\cdot$ duo $\cdot$ in $\cdot$ tibiis $/ /$ zmaragdi $\cdot$ duo $\cdot$ cylindri $\cdot n($ umero $) \cdot X I \cdot$ in spataliis $\cdot z$ marag/di $\cdot n$ (umero) $\cdot$ VIII $\cdot$ margarita $\cdot n$ (umero $) \cdot V I I I \cdot$ in digito $\cdot$ minimo anuli / duo $\cdot$ gemmis - adamant(ibus) $\cdot$ digito $\cdot$ sequenti $\cdot$ anulus $\cdot$ po/lypsephus $\cdot$ zmaragdis $\cdot$ et $\cdot$ margarito $\cdot$ in digito $\cdot$ summo / anulus . cum zmaragdo · in soleis · cylindri n(umero) - VIII. En Antequera, es una estatua de Venus la que recibe sus adornos (HEpOL 3025): Ob honorem civitat [is Romanae?] / signum Veneris cum s[uis ornamentis] / L(ucius) Caesius Fabi[a]nus de[dit? et municipibus?] / omni[bu]s praest[itit?]. No solo las divinidades reciben estatuas ornamentadas, como demuestra la siguiente inscripción procedente de procedente de Loja, Granada (HEpOL 947): Postumia M(arci) f(ilia) / Aciliana Baxo(nensis?) / poni statuam sibi testamen/to iussit ex HS VIII(milibus) n(ummum) item ornamenta septentrio/nem (...).

12. Phillips, 2006.

13. Fest., 416: Statae Matris simulacrum in Foro colebatur; postquam id Cotta stravit, ne lapides igne corrumperentur, qui †plurimis† ibi fiebat nocturno tempore, magna pars populi in suos quique uicos rettulerunt eius deae cultum. Vid. Cic., Leg. II 28 donde alude a Stata standa.

14. Lott, 2004, p. 167. Ejemplos de su eficacia en págs. 3, 79, 98, 168.

15. CIL VI 802 = ILS 3306 = EDCS-17300942: Volcano Quieto Augusto / et Statae Matri Augustae / sacrum / P(ublius) Pinarius Thiasus et / M(arcus) Rabutius Berullus / mag(istri) vici armilustri anni V.

16. Ej. CIL VI 764-6 = ILS 3306-9.

17. Richardson, 1992, p. 428.

18. CIL VI $761=$ ILS 3308. 
sivamente a la más ubicua Fortuna y que esa pudiera ser una de las causas de la escasa presencia de Stata Mater en la epigrafía provincial. Tan escasa que, al margen de este documento, como señala Pastor, nuestra diosa solo se documenta en otras dos ocasiones fuera de Italia, una en Dalmacia ${ }^{19} \mathrm{y}$ otra en Patras. ${ }^{20} \mathrm{~A}$ esas dos menciones, no obstante, hay que añadir una más, recogida en EDCS y procedente de Saranda (Albania), ${ }^{21}$ al margen de las nueve procedentes de Italia. ${ }^{22}$

Aunque resulta en apariencia tentador que Gálico hubiera realizado una acción similar a la de los vicomagistri romanos, lo cierto es que no tenemos ninguna garantía de que el acto religioso del dunviro ilurconense estuviera inspirado en ellos. La donación de una estatua de Stata Mater es prueba de un conocimiento especializado de prácticas religiosas y potencias divinas en desuso, como si de una exhibición anticuarista se tratara. ${ }^{23}$ Es interesante señalar que el dunviro no actúa en la ciudad en la que ejerce su magistratura, sino en un espacio rural, quizá una propiedad suya en la que realiza un ritual preventivo para asegurarse contra los incendios. En efecto, todos los autores desde el descubrimiento de la pieza señalan que apareció junto a otros restos arqueológicos romanos: tegulae, ímbrices, fragmentos de cerámica sigillata y de cerámica común, así como otros restos arquitectónicos, restos de muros y de edificaciones, fragmentos de un molino de mano, y diversos restos cerámicos y óseos, etc., que hacen suponer la posible existencia de una villa en este lugar. ${ }^{24} \mathrm{~A}$ partir de ahí, el acto de Gálico podría ser considerado como un ejercicio inusitado de un experto en materia religiosa que recurre a una estrategia vetusta y, en consecuencia, altamente

19. AE 1910, 81 = EDCS-10101872: Val(etudini) Sta(tae?) sac(rum) / Lurnio Cal() / v(otum) s(olvit) l(ibens). La inscripción está en un altar con representación de la diosa. Fechada entre 1 y 150 d.C.

20. CIL III $500=7256=$ EDCS-27000375: M(arcus) Lollius / Epinicys / aed(ilis $)$ vovit / IIvir / dec(urionum) decr(eto) / Statae matr(i) / de sua pecun(ia) / posuit / sacrum.

21. CIA $265=$ AE 1987, $904=$ AE 2011, $1228=$ EDCS-07400671: [A(ulus) Gr]anius [[---]] / mag(istri)

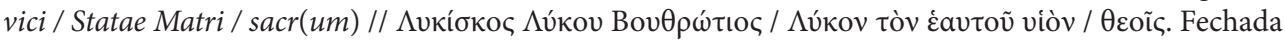
entre 7 a.C. y 14 d.C.

22. CIL XI 3321 = EDCS-22500196; CIL VI 762 = CIL I $994=$ EDCS-17300903; CIL VI $763=$ EDCS17300904; CIL VI 764 = EDCS-17300905; CIL VI 765 = EDCS-17300906; CIL VI 766 = EDCS-17300907; CIL VI 802 = EDCS-17300942; CIL VI 36809 = EDCS-19600479; CIL IX 04113 = EDCS-14805144.

23. En este sentido, nos alejamos de la interpretación de Pastor, para quien el epígrafe respondería al "apego o arraigo a las costumbres y creencias antiguas de los habitantes de las provincias del Imperio" (Pastor Muñoz, 1987-1988, p. 246). De ser correcta su suposición, la veneración a esta diosa estaría más difundida; no se puede sostener una pervivencia cuando no hay testimonios en épocas previas. Por otra parte, con respecto a su extrañeza ante la mención en acusativo del teónimo, baste indicar que es el complemento directo de los verbos dedit y dedicavit. En consecuencia, la ofrenda es la misma diosa representada en la estatua perdida que hubo de estar en el pedestal inscrito.

24. Cf. supra, n. 9. 
cualificada en el risk management, ${ }^{25}$ es decir, la gestión del riesgo frente una amenaza específica, o bien como un agradecimiento a Stata Mater por su protección ante un incendio dominado. ${ }^{26}$

Otro documento que reviste gran interés es el dedicado a Dea Medica. Se trata de un pequeño altar de mármol blanco procedente de Santa Iria, concejo de Serpa, en el distrito de Beja, descubierto en las proximidades del río Guadiana (Fig. 6). ${ }^{27}$ El texto no presenta especiales dificultades de lectura, a excepción del desarrollo de alguna inicial. ${ }^{28}$ Hay consenso en fecharlo de forma imprecisa en el siglo II d. C. Ante la falta de información adicional, se ha considerado que esta Dea Medica estaría relacionada con Minerva ${ }^{29} \mathrm{o}$ con Ataecina, ${ }^{30}$ por su procedencia de la Beturia, o incluso con alguna deidad acuática, lo que justificaría su presencia en una exposición sobre acuaterapia. ${ }^{31}$ Da la impresión de que esa necesidad de vincular a la Dea Medica deriva de la aparente inconsistencia teonímica, acrecentada por un más que dudoso desarrollo de la D de la cuarta línea en D(ominae), lejos de la secuencia onomástica, en lugar de aceptar que se trata del complemento directo de $s$ (oluit) o bien de otro verbo independiente (dedit, por ejemplo). El epíteto Domina es muy frecuente y aparece, en efecto, asociado a Ataecina, pero da la impresión de que se ha forzado demasiado la restitución del texto. Desgraciadamente, la ausencia de información precisa sobre el contexto arqueológico del hallazgo nos impide determinar la identidad de la deidad venerada. La onomástica de la oferente, Procula, frecuente en Lusitania, tampoco permite extraer conclusiones adicionales que no sean meras conjeturas. Ante esta

25. Entre los estudios pioneros sobre la gestión del riesgo es justo recordar los de Mary Douglas: Douglas y Wildavsky, 1982 y Douglas, 2003 (1986). Entre sus primeras aplicaciones históricas, con referencia a la Antigüedad: Covello y Mumpower, 1985, pp. 103-120 = Covello et al., 1986, pp. 519540, donde se establece que el inicio de la reflexión para la gestión del riesgo aparece en Arnobio, cuando en el Contra Paganos defiende las ventajas de aceptar el cristianismo desde una perspectiva lógica formal, lo que Grier había denominado dominance principle (citan un trabajo al que no hemos tenido acceso: Grier, 1981).

26. Obviamente, con esta interpretación nos alejamos de la vinculación en este caso de Stata Mater con Venus, paredro de Vulcano, y de la sugerencia de que su aparición aquí está vinculada al control del "fuego amatorio" (Pastor Muñoz, 1987-1988, p. 246, seguido en http://ceres.mcu.es/pages/Main = CER. ES CE 12975). No parece afortunado pensar que todo el operativo cultual de Gálico esté relacionado con un absceso amatorio.

27. García, 1991, p. 427, n 403; Canto Montemolín, 1997, p. 167, nº 204.

28. $E R B C 204=A E$ 1955, 241 = Cardim Ribeiro y Alves Fernandes, 2002, p. 423, nº 90 (con foto) = HEpOL 5219: Deae Medicae / Procula / Rufi filia / D(ominae) ex u(oto) a(nimo) l(ibens) s(oluit).

29. Es la opción de García, 1991, p. 427, n 403.

30. Solución preferida por Canto Montemolín, 1997, p. 167, nº 204.

31. Andreu Pintado, 2017. El epígrafe aquí presentado corresponde al nº 15.2 del catálogo de ese libro. 
situación, solo podemos plantear dos explicaciones alternativas a la omisión del teónimo de la diosa: o bien este nombre fue obviado por consabido, esto es, porque la adscripción divina del lugar donde estuvo instalado el altar resultaba suficientemente explícita como para justificar su elusión, y en este caso la Dea de atribuciones medicinales sería quizás Minerva, o bien la omisión del teónimo se debió a que la propia oferente dudaba acerca de la identidad de la diosa que había respondido a su votum. Si este último fuera el caso, Procula habría recurrido a una estrategia de risk management en su comunicación con lo sobrenatural, pues al dirigirse a la deidad por su función o por el efecto salutífero que habría tenido sobre ella en lugar de por su nombre, habría evitado el riesgo de equivocarse en la elección de la deidad.

Igual complejidad presenta un unicum epigráfico inscrito en un altar hallado en un pozo de un cortijo a cinco kilómetros de Osuna (Sevilla). El texto epigráfico nos hace saber que Q. Avidius Augustinus ofrece el altar al Arbor Sancta (Fig. 7). ${ }^{32}$ Fue un acierto de Antonio Blanco Freijeiro identificar el destinatario de la acción religiosa poniéndolo en relación con los ritos del culto de Atis. ${ }^{33}$ Propuso este autor que la expresión arbori sanctae había de entenderse como sinónima de Attidi sancto o sancto Attidi, ${ }^{34}$ en virtud de la fiesta del arbor intrat que se celebraba el 22 de marzo y que culminaba con la celebración de las fiestas Hilarias. ${ }^{35}$ Un trabajo de Diosono, en el que repite lo que ya había escrito Blanco sobre el epígrafe y las fiestas a las que remite la advocación de nuestra inscripción, añade una precisión innovadora, pues la expresión arbor sancta aparece en Roma como topónimo citado por los Catálogos Regionales del siglo IV y, además, se sitúa en la Notitia Regionum II entre el Caput Africae y los Castra Peregrina, cerca de la parte superior del Celio; de este modo, el topónimo se ha identificado por muchos autores con la Basílica Hilariana, ${ }^{36}$ sede del collegium dendrophorum. La reiteración del topónimo y de la secuencia teonímica del epígrafe de Osuna confirma la conexión de Arbor Sancta con el pino sagrado identificable con el dios Atis. ${ }^{37}$

32. CIL II $2 / 5,1112=$ CILA II $613=$ CCCA V $161=$ HEpOL 3353: Arbori / sanctae / Q(uintus) Avidius /Augustinus / ex visu posuit.

33. Blanco Freijeiro, 1968, pp. 91-100.

34. ILS $4149=$ CIL VI 501; ILS $4117=$ CIL VIII 7956.

35. Tras Blanco, todos los autores han repetido su interpretación: Ortiz Ayala, 1988, pp. 441-453. El Boletín del Fichero Epigráfico publica ahora en forma de artículos las fichas catalográficas de sus redactores, aunque no presenten ninguna aportación a lo consabido. La que aquí se comenta corresponde a Serrano Ordozgoiti, 2018, pp. 26-30.

36. Palazzo y Pavolini, 2013.

37. Diosono, 2006. 
Lo que ningún autor ha discutido es la contundente afirmación de Blanco según la cual la fórmula ex visu era consecuencia de una incubatio..$^{38} \mathrm{La}$ frecuencia de tal fórmula ha hecho sospechar que se trata de un lugar común, independiente de la razón verdadera que haya podido conducir al devoto a ofrecer su testimonio. En efecto, la incubatio requiere unas condiciones de espacio, personal y organización que se documentan consistentemente en la parte grecohablante del Imperio, pero no en la occidental..$^{39}$ Por ello, la fórmula ex visu no ha de asociarse a la incubatio, sino que responde a una particular predisposición anímica del dedicante; no obstante, no es una estrategia personal de comunicación con lo sobrenatural, sino una muletilla justificativa de su acción ritual.

El epíteto cualitativo inherente con el que se exalta al Arbor no responde a una praxis propia del ámbito rural, sino que se corresponde con la terminología propia del culto atideo que, en esta ocasión, encuentra un marco referencial infrecuente, ya que el culto de los dioses frigios es casi exclusivamente urbano. El hallazgo rural de este testimonio tal vez pudiera explicarse por una conexión del lugar con un hipotético espacio sacro en la colonia de Vrso dedicado al culto metróaco y atideo, por ejemplo, un lucus del que anualmente se extrajera el Árbol Santo que daría comienzo a la procesión del Arbor Intrat y a la gran celebración de las fiestas metróacas. ${ }^{40}$

Más característico de un ámbito extraurbano es el culto de los Lares Viales, protectores de las vías de comunicación y de las encrucijadas campestres, a quienes se encomendaban los romanos cuando partían de viaje. ${ }^{41}$ En la primera mitad del siglo I d.C., un altar les fue consagrado en un hábitat de villas romanas en el ager de Ilurco (Granada) que conforma hoy el yacimiento del paraje denominado El Caserón u Olivar de los Caserones. ${ }^{42}$ El dedicante, Titus Papirius Severus, es sin duda la misma persona que dedicó una estatua al emperador Tiberio en la ciudad de Ilurco (Cerro de los Infantes, Pinos Puente, Granada). ${ }^{43}$ No hay información sobre su cursus hono-

38. Blanco Freijeiro, 1968, p. 99. Aunque este autor muestra cierta prudencia, sus seguidores lo afirman con contundencia.

39. El viejo artículo de Fernández Fuster, 1950, ha quedado como reliquia historiográfica frente al estudio de Renberg, 2017, donde tras un extenso análisis concluye que en occidente la práctica de la incubatio es inexistente.

40. Sobre estos asuntos véase Pavolini, 2016, pp. 337-348.

41. Santos Yanguas, 2012, p. 174.

42. Beltrán Fortes, 1982-1983 = CIL II ${ }^{2} / 5,701=$ AE 1986, $380=I L P G r a n a d a 164 b=H E p O L ~ 2800:$ T(itus) Papirius / Severus / Laribus v(ialibus) v(otum) s(olvit).

43. CIL II $2 / 5,677=$ CIL II $2062=$ ILPGranada $99=$ HEpOL 2777: Ti(berio) Caesari divi Aug(usti) f(ilio) divi Iuli / n(epoti) Augusto pont(ifici) max(imo) trib(unicia) / potes(tate) XXVIII co(n)s(uli) IIII imp(eratori) VIII / auguri XVvir(o) s(acris) f(aciundis) VIIvir(o) epulonum / T(itus) Papirius Severus. 
rum ni sobre su filiación, lo que nos hace dudar sobre su estatus socio-jurídico, pero posiblemente pertenecía a la élite municipal. Su gentilicio, Papirius, no es común en la epigrafía hispana. Un C. Papirius, romano de la tribu Cornelia, es el autor de una dedicación de época augustea aparecida en Osuna, mientras que los Papirii Aelianii son una familia senatorial que tiene su auge en el siglo II d.C. en Iliberris, la ciudad más importante de Granada junto con Ilurco. ${ }^{44}$

El yacimiento de El Caserón u Olivar de los Caserones se encuentra ubicado en el Valle del Genil, en la Antigüedad un lugar de paso obligado entre la Andalucía oriental y la occidental, pues por él transcurría un ramal de vía que conectaba Astigi con Acci a través de Anticaria e Iliberris. Por consiguiente, es lógico pensar que nuestro altar era una de las aras que se erigían en capillas o lararios al borde de los caminos para rendir culto a sus Lares protectores. ${ }^{45}$

Como queda constatado en el artículo de José Carlos López en este mismo volumen, la veneración de los Lares Viales hunde sus raíces en la Roma republicana, donde estaba ligada al culto de otros Lares tutelares de la ciudad y de sus habitantes, como los Compitales y los Semitales. ${ }^{46}$ Sin embargo, la presencia de los Lares Viales en la epigrafía de Italia y del resto del imperio, a excepción de Hispania, es muy escasa. Apenas están documentados por media docena de inscripciones procedentes de Roma, Falerii en Etruria, Portus Magnus (Viel Arzew) en Mauretania y Sarmizegetusa en Dacia, a las que cabría añadir una dedicación de Narbona a los Lares Viatores. ${ }^{47}$ En Hispania, en cambio, el número de testimonios de estos dioses asciende a 51, todos procedentes del Noroeste peninsular salvo un altar hallado en Denia, analizado por José Carlos López en su contribución a este volumen, y el altar del ager Ilurconensis que aquí nos ocupa.$^{48}$ Semejante concentración de documentos en el Noroeste hispano ha llevado a una mayoría de estudiosos a sostener la hipótesis de que tras los Lares Viales venerados en esta área subyacen deidades locales de sustrato hispano-céltico. Estos numina loci, sin embargo no documentados, habrían sido identificados con los Lares romanos a través de un proceso de

44. Beltrán Fortes, 1982-1983, p. 240.

45. Beltrán Fortes, 1982-1983, p. 241.

46. Vid. J.C. López Gómez en este volumen, pp. 209-237. Los Lares Viales son mencionados por Plauto, Mercator 865 y Varrón, De ling. lat. VI 25.

47. CIL VI 36810-36812 (Roma, tres altares hallados cerca de la Via Portuensis, consagrados respectivamente a los Lares Semitales, los Lares Curiales y los Lares Viales); CIL XI 3079 (Falerii); CIL VIII 9755, de lectura dudosa (Portus Magnus); CIL III 1422, con mención de solo un Lar Vial, en singular (Sarmizegetusa); CIL XII 4320 (Narbona).

48. Corell, 1999, n 176 = HEpOL 14997 (Denia). Cf. Gómez Vila, 2004, pp. 138-153; Abascal Palazón, 2019. 
interpretatio fundamentado en la similitud de funciones de unos y otros dioses. La abundante presencia de Lares de gentilidades locales en la misma zona parece responder al mismo fenómeno, por lo que refuerza esta interpretación. ${ }^{49}$

Ciertamente, esta hipótesis es la mejor explicación propuesta hasta la fecha para la elevada incidencia de los Lares Viales en el territorio noroccidental de Hispania. No obstante, el culto a estas divinidades no tiene por qué responder en todas las ocasiones a dicho fenómeno de interpretatio. Esto es especialmente cierto en el caso de los altares de Denia y del ager Ilurconensis, que no pueden vincularse con la realidad observada en el Noroeste. Por el entorno de explotación agropecuaria en el que aparecen y por la identidad de sus dedicantes, se presentan más bien como testimonios del culto a los Lares romanos protectores de los caminos y de sus viandantes. ${ }^{50}$ Asimismo, aunque la esfera de acción de los Lares Viales está vinculada a un ámbito territorial y socioeconómico extraurbano, estos dioses no pueden considerarse como una expresión religiosa rústica, pues están plenamente integrados en la religión romana practicada en las ciudades y son venerados mediante el mismo lenguaje ritual que las deidades ligadas al ámbito urbano.

El resto de divinidades documentadas en el territorio rural bético no revisten un carácter singular susceptible de ser interpretado como característico de una hipotética praxis religiosa rústica. ${ }^{51} \mathrm{Al}$ contrario, se encuentran estrechamente ligadas a la religión cívica y, por consiguiente, ponen de manifiesto la penetración de manifestaciones religiosas del mundo urbano en el campo. Por ejemplo, un altar hallado en una villa cerca de Andújar, por tanto dentro del antiguo territorio de Isturgi, fue consagrado por una liberta, Sempronia Flaviana, a Júpiter Óptimo Máximo Conservator generis humani. ${ }^{52}$ Esta designación forma parte de la titulatura imperial en otras dos dedicaciones de la Bética y en una de Numidia, dirigidas respectivamente a Trajano,

49. Lambrino, 1965, pp. 233-235; Alarcâo, Étienne y Fabre, 1969, p. 227; Acuña Castroviejo, 1971; Mangas Manjarrés, 1983; Bermejo Barrera 1986; Beltrán Lloris, 1993, pp. 63-64; Gonzáles Fernández y Rodríguez Colmenero, 2002, pp. 245-247; Prósper Pérez, 2002, pp. 277-281; Marco Simón, 2007a, pp. 198-202; Gil Mantas, 2010, pp. 13-34; Santos Yanguas, 2012, pp. 175-177. Vid. J.C. López Gómez en este volumen, pp. 209-237.

50. Beltrán Fortes, 1982-1983, p. 241.

51. Habría sido muy interesante tratar en profundidad, como ejemplo de epíteto toponímico, el atributo de Lybicus Hercules, pero el epígrafe es falso, por lo que no merece la pena prestarle atención adicional en este contexto. CIL II/5, ${ }^{*} 3=$ CIL II/5, ${ }^{\star} 147$ = EDCS-41300125: Libyco Herculi deo invicto / statuam $\arg ($ enteam ) / C L P civitas martis / D S P P P.

52. AE 2003, $929=$ HEp 13, 2003/2004, $353=$ HEpOL 25178: I(ovi) O(ptimo) M(aximo) K(apitolino $) /$ Conservatori gene/ ris · humani / Sempronia . Fla/viana $\cdot L($ uci $) \cdot$ lib (erta) $\cdot /$ v (otum $) \cdot$ s $($ olvit $)$. 
Marco Aurelio y Antonino. ${ }^{53}$ La devota venera así a Júpiter en cuanto dios tutelar del orbe del emperador, esto es, de la ciudad de Roma y de su imperio.

\section{ELENCO DE EPÍtetos SELECCIONADOS}

Los epítetos operacionales institucionales políticos de poder constituyen la tipología dominante en la epigrafía bética. Dentro de esta, el apelativo mayoritario es Augustus/a, que se aplica a Mercurio, Fama, Salus, los Lares y las ninfas. Damos por superado el período en el que se consideraba este epíteto como testimonio de culto imperial. En realidad, la generalización de su empleo parece indicar que el poder político ha dado en préstamo una titulación a los dioses mediante la cual se podría ensalzar inicialmente al emperador y a su domus, para terminar convirtiéndose en una expresión formularia sin otro valor que la preservación de la exaltación del modelo político transferido a la esfera divina. ${ }^{54}$ Creemos que Augustus/a funcionaba principalmente como un título de respeto susceptible de ser atribuido a cualquier divinidad y carente, salvo en casos puntuales, de un vínculo directo con el poder imperial. En efecto, en lo que respecta a este último aspecto, no parece en líneas generales que los devotos buscasen expresar su lealtad personal hacia la familia imperial mediante el uso de este epíteto, ni poner los poderes del dios al servicio de la institución imperial. No obstante, esto no impide que ciertos cargos sacerdotales ligados al culto imperial, como es el caso de los séviros augustales, muestren una especial inclinación por el uso de este apelativo de poder, que resultaría especialmente familiar en su ámbito operativo.

Ciertamente, los séviros augustales abundan entre los dedicantes a deidades augustas tanto en la ciudad como en el campo de la Bética. En este último espacio, una dedicación a Mercurio Augusto proveniente de Utrera fue ofrecida por un li-

53. CIL II $2 / 5,730=$ CIL II $2054=$ ILS $304=$ HEpOL 2981 (Antequera - Cauche el Viejo, Málaga): Imp(eratori) Caesari divi Nervae f(ilio) / divo Traiano Optumo (!) / Aug(usto) Germ(anico) Dacico Parthico / pontif(ici) max(imo) trib(unicia) potest(ate) XXI imp(eratori) / XIII co(n)s(uli) VI pater(!) patriae optumo(!) / maxumoque(!) principi con/servatori generis humani / res publica Aratispitanorum / decrevit divo dedicavit; CIL II $/ 5,59$ = CILA III 69 = HEpOL 1982 (Torredonjimeno, Jaén): Imp(eratori) Caesari / $M($ arco) Aurelio $[A]$ nto $[n]$ ino Aug(usto) $[p$ (ontifici)] m(aximo) / Armeniaco $P[a]$ rthico maximo / Medico tribuniciae pot(estatis) XX imp(eratori) V/co(n)s(uli) III p(atri) p(atriae) divi Antonini fil(io) [Divi] / Hadriani nepoti divi Traiani $P[\operatorname{arth}(i c i)] /$ pro[nepo]ti divi Ner[vae] a[bne]p[oti] / conser [v]atori generis hu[mani] / ob honorem pontifica[tus] / M(arci) Sergii Materni mariti / Annia Q(uinti) fil(ia) Severa / epulo diviso editis circe(n)sibus / po [su] it / et d(edicavit). CIL 08, 19919 = EDCS-13003602 (Nechaa er Rihane): Divo M(arco) Antonino / Pio Germanico Sar[ma]/tico conservatori [ge]/neris humani patri [---].

54. Sobre este complicado asunto ahora es imprescindible acudir a las reflexiones de Villaret, 2019. 
berto séviro augustal. ${ }^{55}$ Otro séviro augustal dedica un altar a los Lares Augusti en el ager Iulipensis, Badajoz. ${ }^{56}$ En una villa o mansio situada en la actual Usagre, en Badajoz, un liberto honra a Salus Augusta con la erección de un altar. ${ }^{57}$ El estatus socio-jurídico de los dos otros dedicantes a divinidades augustas es incierto. ${ }^{58} \mathrm{He}-$ cho destacable es que los relativamente abundantes testimonios de Augustus/a en el ámbito rural bético contradicen la conclusión global de Alain Villaret, según la cual es reducida la presencia de este apelativo en el ager, así como las conclusiones de los estudios de los epítetos rurales de Tarraconense y de Lusitania publicados en este mismo volumen. ${ }^{59}$ En efecto, en el litoral tarraconense y en el interior de los conventus Carthaginiensis, Tarraconensis y Caesaraugustanus, los epítetos institucionales relacionados con el poder político, especialmente Augustus/a, se concentran casi exclusivamente en las ciudades. ${ }^{60}$ Lo mismo sucede en el campo lusitano, donde además los escasos epítetos de poder hallados en zonas rurales se corresponden esencialmente con la atribución del título Domina a la diosa Ataecina. ${ }^{61}$ En la Bética, en cambio, los epítetos de poder, con Augustus/a a la cabeza, son la categoría dominante tanto en el campo como en la ciudad, a pesar de que sean naturalmente mayoritarios en este último espacio. El 30,6\% de los epítetos rurales de esta provincia son de poder (un total de 11 testimonios, de los cuales 6 corresponden a Augustus/a y 5 a Dominus/a), una tipología de epítetos que en la ciudad alcanzan el 53\% (90 testimonios de Augustus/a y 17 de Dominus/a y 4 de Regina).

Dominus/a, el segundo epíteto de poder constatado en el campo bético, se asocia a Ataecina en una ara de mármol hallada en una finca de Bienvenida (Badajoz) (Fig. 8). El mal estado del altar en su lateral izquierdo y especialmente en la parte inferior dificultan una lectura segura, pero la cadena onomástica de la divini-

55. CILA II 986 = I.Utrera $65=$ HEpOL 4954: [Me]rcurio Au[g(usto) / sacru $] m$ P(ublius) Rutili $/[u s$ P(ubli) Rut(ili)] Fabiani lib(ertus) / [---VI]vir Aug(ustalis).

56. EE IX $252=$ CIL II $/ 7,938=$ HEpOL 4511: Laribus $・$ Aug(ustis) / aram / L(ucius) • Cornelius / Firmillus / Augustalis / d(e) $\bullet$ s(uo) $\bullet d($ edit $) \cdot d($ edicavit $)$.

57. AE 1962, $74=$ IMBA $52=$ HEPOL 20099: Saluti $\cdot \operatorname{Aug}($ ustae $) \cdot /$ L(ucius $) \cdot$ Petronius $\cdot L($ uci) $\cdot$ lib(ertus) / ---].

58. CIL II²/5, 903 = HEpOL 951: Sacrum / Famae /Aug(ustae); AE 1992, $1503=$ HEpOL 229: Nym[ph] is / Aug(ustis) s(acrum) $\cdot M($ arcus $) \cdot /$ Antonius / [libe(ns)] v(otum) a (nimo) s(olvit).

59. Villaret, 2019, p. 333. Según este autor (Villaret, 2019, p. 539), el 93,8\% de los epítetos augusteos en Hispania procede de ciudades latinas o romanas, y solo una minoría de zonas rurales. Vid. A. Beltrán Ortega y J.C. López Gómez en este volumen, pp. 209-237 y 239-269.

60. J.C. López Gómez en este volumen, pp. 209-237.

61. A. Beltrán Ortega en este volumen, pp. 239-269 
dad parece clara, pues se trata de Domina Ataegina Turubriga, a la que se acompaña de algo que le es propio, pero que no sabemos de qué se trata; la restitución de las líneas finales es muy especulativa, pues no hay manera de de saber si el verbo es singular o plural y, en consecuencia, quién o quiénes son el sujeto. ${ }^{62}$ La zona de la que procede ha proporcionado ya otros monumentos dedicados a la misma diosa, presente tanto en ámbitos urbanos como rurales, por lo que no hay nada especialmente significativo en la información extraíble. ${ }^{63}$

A una Do(mina) S(ancta) se dirige también Iulius Felix en un altar hallado en Cabeza la Vaca (Badajoz), empotrado en la fuente del Coso (Fig. 9). El estado de la pieza no nos permite asegurar que la restitución del texto sea correcta y que, en consecuencia, se pueda reconocer a Ataecina en esta dedicatoria. ${ }^{64}$ Que se trate de un objeto de contenido religioso es incuestionable, porque el bloque tiene forma de altar. El lapicida no es habilidoso, ni cuidadoso si tenemos en cuenta la organización del texto en el campo epigráfico. Especialmente inapropiada parece la mención de la presunta deidad, simplemente enunciada mediante la inicial de un posible epíteto y dos letras de un segundo, sin mención del teónimo, para el que quedaba campo epigráfico. De hecho, es un acto de fe aceptar la restitución de las letras DOS y que estas, a su vez, respondan a una Do(mina) S(ancta). La D inicial no es segura y el trazado permitiría pensar en una L, lo que alteraría toda la interpretación del texto.

Domina es también Isis en una inscripción perdida que un testimonio erudito del siglo XVI sitúa en un oppidum ignotum, Torre de Miguel Sesmero (Badajoz). Según el texto transmitido, una mujer, Escandilia Campana ofrece algo que ignoramos a la Señora Isis en su testamento. ${ }^{65}$ Isis aparenta ser aquí venerada en su condi-

62. Esteban Ortega, 1984, pp. 21-25 foto $(A E$ 1987, 472) = López Melero, 1986, pp. 93-112 foto (HEp 1, 1989, 81; AE 1991, 956) = HEpOL 5232: Domina / [A]ttaegina / [T] urubriga[e --- / -c.3-]tiribus • suis / collectis / ma(gistri) $\bullet f($ ecerunt $) /[v($ otum $)]$ s(olverunt $)[a($ nimo $) l($ ibens $)]$. Variante: Domina $[$ e I A] ttaegina(e) / [T] urubriga(e) / [---]tiribus suis / collectis / ma(gistri?) f(ecerunt?) / S. Se conserva en propiedad particular.

63. Una dedicación a Dea Ataecina Proserpina Turibrigensis procede de Salvatierra de los Barros, en Badajoz: ERBC 89 = HEpOL 5568. Véase A. Beltrán Ortega en este volumen con respecto a los testimonios de esta diosa procedentes de Lusitania, pp. 239-269.

64. HEp 5, 1995, 64; AE 1997, 822 = HEp 7, 1997, 60 = HEpOL 735: [I] ulius Fe/lix Do(minae) S(anctae).

65. Inscripción recogida por Docampo en el siglo XVI (F. Docampo, Los quatro libros primeros de la crónica general de España, Zamora, 1544, f. 20v y 146). Se ignora todo lo concerniente a las condiciones de su hallazgo, así como su paradero actual. Según Docampo el texto decía: Isidi Dominae / ex testamento / Scandiliae C(ai) f(iliae) Campanae. CIL II 981; García y Bellido, 1967, p. 113, n 12; SIRIS 754; Mora, 1990, I, p. 499, n 54; RICIS 601/0301; Dardaine et al., 2008, p. 161; Alvar Ezquerra, 2012, n 
ción de "Señora de los Manes", la que respetan "los dioses del infierno" (Apul., Met. XI 5 y 25; vid. Belo VIII, p. 161). El epíteto Domina se generaliza, según todos los indicios, a partir de época Flavia, en coincidencia con el uso del término dominus/ dominatus para expresar la modalidad propia del gobierno de los Flavios (Domiciano se hizo llamar desde el año 85/86 Dominus et Deus). ${ }^{66}$ Conviene, no obstante, recordar que este epíteto de poder se documenta con anterioridad a dicha época. ${ }^{67}$ El momento de mayor frecuencia de uso parece corresponder con el reinado de Adriano, por lo que no es casual que Isis sea una de las divinidades a la que más asiduamente se llama Domina. ${ }^{68}$

En su versión masculina, se ha defendido la existencia de su empleo en un bloque de mármol, dañado en todos sus lados, lo que dificulta la lectura, con el agravante del uso de abreviaturas que se han desarrollado como $D$ (omino) De[o Patri (?)]. El monumento fue hallado en Serpa, distrito de Beja (Portugal).$^{69} \mathrm{De}$ esa misma localidad procede el altar dedicado a la Dea Medica, al que prestamos atención páginas atrás, así como otra inscripción dedicada a Liber Pater, ${ }^{70}$ lo que supone un cierto apoyo a la restitución del epígrafe objeto de este comentario. A ello se añade la posible relación de parentesco entre Sev(erus), oferente del bloque de mármol, y Sever(a), partícipe en el exvoto dedicado a Liber Pater.

Un último documento en el que el término Dominus aparece en la cadena onomástica es un altar encontrado en el ager del municipio romano de Solia, Villanueva de Córdoba (Córdoba), dedicado a Marte. ${ }^{71}$ La vinculación de Marte con el apelativo Dominus se convierte en enunciado onomástico formular, como se pone de manifiesto en el conjunto epigráfico de Hagenbach (Worth am Rhein, Alemania), datado en el siglo III, donde se invoca a Marte con el epíteto Dominus. ${ }^{72}$

C062 (http://biblioteca3.uc3m.es/Gens-Isiaca-Hispania/consulta.php? contenido=consulta\&tipo=C.B\& pieza=Ins); HEpOL 816.

66. Cf. Malaise, 1972, pp. 414-417.

67. No faltan ejemplos anteriores, como parece ser el caso de un ara dedicada a Domina Caelestis, que se fecha entre el siglo I a.C. y el I d.C. Cf. Uroz Rodríguez, 2012, p. 356.

68. Acerca de Adriano y los cultos isíacos, véase recientemente Muñiz Grijalvo, 2019.

69. $\operatorname{ERBC} 206=\operatorname{HEp} 7,1997,1149=$ HEpOL 23399: D(omino) $\cdot \operatorname{De}[$ o Patri(?)] $/ \operatorname{Sev}[\operatorname{erus}(?)] / d(e)$ $s($ uo $) f(e c i t)$.

70. ERBC $205=$ RAP $386=$ HEpOL 5220: Deo $\cdot$ Libero $/$ Patri $\cdot$ ex vot $[o] /$ Plotia $\cdot$ Sever $[$ a et $] /$ Vale $($ rius $)$ Crescaniu/s v(otum) a(nimis) s(olverunt) $d($ ie) III Kal(endas) $M($ ar $) t($ ias $) /+++++$.

71. AE 1986, 362 = CIL II²/7, 778 = HEpOL 4378: [-] Porciu[s / ---] Fron[to / d]omin[o / M]arti a[ni]/ mo libe $[n s]$.

72. Cf. AE 1999, 1127-1134, 1137-1140, 1142, 1144, 1145, 1148, 1152, 1160. 
Estos documentos ponen de manifiesto que el epíteto Dominus/a se emplea indistintamente para deidades variopintas, por lo que no puede interpretarse como un atributo que especifica una cualidad distintiva de la divinidad. Al contrario, expresa un tratamiento específico de respeto y sumisión, más acorde con la estrategia cultural colectiva de comunicación con la divinidad que con las opciones personales para la gestión de la relación con lo divino, pues de hecho, no se percibe a partir del estudio de los individuos involucrados en los actos religiosos de los epígrafes recogidos ninguna conexión entre el empleo de este epíteto de poder y eventuales relaciones sociales de hegemonía o de dependencia. En consecuencia, el uso del epíteto Dominus/a no sirve como demarcador de diferentes usos cultuales, pues su uso es indistinto e indiferenciado en el ámbito urbano y en el rural.

Algo similar podríamos decir a propósito del empleo de Sanctus/a, documentado en cuatro ocasiones en el territorio rural de la Bética. Se trata de un epíteto cualitativo inherente que tiene un efecto intensificador de la condición divina del ente al que se dirige el mensaje. Es en este sentido redundante su empleo en el caso ya mencionado de la Do(mina) S(ancta) de Cabeza de Vaca, en el que la exaltación de la divinidad, quizá Ataecina, se expresa mediante un epíteto de poder y uno aclamatorio ${ }^{73}$ referido a la cualidad inherente a la divinidad venerada. En el caso igualmente analizado de Arbor Sancta, su uso se manifiesta necesario para establecer el carácter sagrado del árbol referido. En este caso, habría sido equivalente a designar a la deidad como Arbor Dea, es decir, estableciendo una cualidad intrínseca que no solo expresa su carácter sacro, sino que incide en una forma específica de exaltación que pasaría más inadvertida de haber empleado este segundo elemento especificativo.

También es sancta Proserpina en una inscripción hallada en una zona de $v i$ llae en el territorio de Ilia Ilipa (Castilblanco de los Arroyos, Sevilla), costeada por $L$ (ucius) Samnius Sulla, un ingenuus que se da a conocer con sus trianomina. ${ }^{74} \mathrm{De}$ doce inscripciones dedicadas a Proserpina en $H E p O L$, tres tienen el apelativo sancta, lo que lo convierte en su epíteto más habitual. ${ }^{75}$ En el caso que nos ocupa no apreciamos nada que pueda ser interpretado como una acción ritual específicamente rural.

Un último uso del apelativo sanctus corresponde a la secuencia onomástica Numini sancto deo / Silvano que aparece en un altar hallado en un cortijo del ager

73. "Celebratory type" dice Parker, 2017, pp. 11-15.

74. CIL II $1044=$ CILA II $336=$ HEpOL 863: Proserpinae / sanctae sacru/m L(ucius) Samnius Su/lla voto sani/tate condemnat [us] / an(imo) [---]d(edit).

75. HEpOL 863, 21233, 21480. 
Obulconensis (Jaén) (Fig. 10) ${ }^{76}$ En él, Successianus, un esclavo imperial, que emplea el posesivo como muestra de orgullo, costea entre 131 y 170 d.C., con ayuda de sus familiares, un precioso altar dedicado a su divinidad favorita, Silvano, considerado como numen santo y dios a un tiempo; es decir, la cualidad de dios es ratificada con otro elemento de distinción equivalente, numen. Silvano es, en consecuencia, objeto de una exaltación específica y redundante, estrategia comunicativa del oferente que despliega recursos en distintas direcciones. Por un lado, la secuencia onomástica del dios escogido opera sobre él un insistente agradecimiento por su indiscutible potencial divino; por otra parte, la mención de sus queridos augustos tiende a construir un lazo de proximidad aprovechando su propia condición servil; finalmente, al integrar a los suyos en la erección del altar, los poderes aludidos en el texto toman bajo su tutela a los parientes de Successianus. Concurren en el documento elementos que permiten pensar que estamos ante un hecho no necesariamente singular, pero sí motivado por las condiciones vitales de Successianus, en su condición de esclavo en una posible explotación imperial que implora a una deidad protectora de los campos y de los bosques, donde se desarrollaría la actividad laboral del esclavo. No desearíamos dejarnos llevar con especulaciones derivadas de la escasa información que tenemos a nuestra disposición. Ciertamente, este altar u otro similar podría haber aparecido en ámbito urbano y entonces estaríamos trabajando con otras especulaciones que nos dieran satisfacción; del mismo modo que si en lugar de alguno de los epítetos presentes hubiera aparecido un Augusto, por lo demás frecuente, ${ }^{77}$ también estaríamos elaborando consideraciones generales a partir de un hecho circunstancial.

Lo cierto es que Silvano es muy versátil, ${ }^{78}$ tanto que llega a ser un dios total, como se expresa en una inscripción procedente de Itálica (Sevilla), en la que, Autarces, un liberto de la emperatriz Sabina ruega por la salud de Adriano y de la propia Sabina a Silvanus Pantheus; $;^{79}$ es decir, atribuye al dios un apelativo relacio-

76. CIL II ${ }^{2}$ /7, 131 = CILA III 293 = HEpOL 3706: Numini sancto deo / Silvano / Successianus Aug(usti) $n$ (ostri) s(ervus) / ex voto cum suis posuit.

77. No es una especulación gratuita, pues un altar de Isturgi (Andújar) lleva la siguiente inscripción $\left(C I L \mathrm{II}^{2} / 7,58\right.$ = CILA III 267 = HEpOL 3655): Silvano / Aug(usto)/Runcani/us Vic/tor op/tio coh(ortis) / I Asturu(m) / [e]t Call(aecorum) / [---]. ¿Se atrevería alguien a afirmar que este solo podía haber aparecido en contexto urbano y el de Successianus en contexto rural? ¿No podría ser perfectamente intercambiable el lugar de hallazgo?

78. Dorcey, 1992.

79. ERItalica $35=$ CILA II 369, fig. 205 = HEpOL 543: Pro salute Hadriani Aug(usti)/ et Sabinae Augustae n(ostrae) / Silvano Pantheo Autarces / Sabinae Aug(ustae) n(ostrae) lib(ertus) / ex voto. 
nal jerárquico de superioridad ${ }^{80}$ en el que se acumulan todas las potencialidades divinas para alcanzar la salud de la pareja imperial. ${ }^{81}$ El apelativo no hace referencia a una acumulación o amalgama, sino que proyecta en una sola divinidad, sin negar a las restantes, la totalidad de los poderes divinos. Por ello, este epíteto no es exclusivo de una deidad, sino que es una exaltación totalizadora de la divinidad invocada en cada caso.

Isis también es Panthea y, además, en ámbito rural. En el cortijo de la Rentilla, a unos $10 \mathrm{~km}$ al sur de Montilla se recuperó en la década de los 90 un altar que se conserva en el Museo de Antequera.$^{82}$ En Pax Iulia estaba documentado un Serapis Pantheus ${ }^{83}$ pero esta es la primera vez en Hispania que Isis recibe el apelativo de Panthea. ${ }^{84}$ Ignoramos completamente las circunstancias que concurren en la elección de este epíteto cualitativo con efecto aclamatorio, pues el texto epigráfico es lamentablemente demasiado breve. Se ha señalado que cerca del hallazgo de este altar apareció una inscripción consagrada a Ceres, lo que podría iluminar el carácter agrario de ambas devociones, dada la actividad económica de la zona. ${ }^{85}$

Aún quedaría un documento de gran interés por lo insólito del epíteto transmitido. Un manuscrito de la Biblioteca Nacional ( $\mathrm{n}^{\circ}$ de inventario 8.398) reproduce una inscripción dedicada a Mercurio Supernus. ${ }^{86} \mathrm{Al}$ parecer el monumento, presumiblemente un altar, fue visto en Puebla de Alcocer (Badajoz). Del dedicante prácticamente no sabemos nada, pues solo se identifica con dos iniciales, Q y P; tal vez se trate de un ingenuo. Lo que más nos interesa en este estudio es precisamente el epíteto Supernus. Propone la editora de este epígrafe de transmisión manuscrita que Supernus aquí no debe ser entendido en su acepción del que está encima, sino

80. Un primer intento de análisis de este epíteto y entidad divina en Hispania, ahora superado, es el de Mangas Manjarrés, 1991, pp. 111-132. Para una perspectiva más compleja: Cadotte, 2002, pp. 38-39, 55-72; Mitchell, 1999, pp. 81-148; Belayche, 2010, pp. 34-55; 2011, pp. 139-174; 2020, pp. 87-115.

81. Vid. Alvar Ezquerra, e.p.

82. Beltrán Fortes y Atienza, 1996, pp. 183-184, lám. III $=$ CIL II²/5, $575=$ RICIS 602/0701 = Beltrán Fortes y Mercado Hervás, 2010, p. 1138, n. $17=$ Alvar Ezquerra, 2012, n C.B.18.01 = HEpOL 2514: Sacrum / Pantheae / Isidi.

83. RICIS 601/0201 = Alvar Ezquerra, 2012, $n^{\circ}$ C.L.06.01 = HEpOL 21126: Serapi Pantheo / sacrum / in honorem C(ai) Ma/ri Prisciani / Stelina Prisca / mater filii / indulgentissimi d(ono) d(at).

84. En Mainz también se atestigua una Isis Panthea (RICIS Suppl. II 609/0503 = EDCS-33900059): Pro salute Augustorum et / s(enatus) p(opuli)q(ue) R(omani) et exercitus / Isidi Pantheae Claudia Aug(usti) l(iberta) Icmas / et Vitulus Caes(aris) sacer(dote) Claud(io) Attico lib(erto).

85. CIL II²/5, $574=$ HEpOL 2513: Sacrum / Cereri.

86. Hernando Sobrino, 2003, $\mathrm{n}^{\circ} 317=$ HEpOL 24479: Mercurio / Super/no $\cdot$ Q(uintius $) \cdot P(---$ ?) / $v($ otum $) \cdot a($ nimo $) \cdot l($ ibens $) / s($ olvit $)$. 
en la de celestial. En efecto, Ovidio, Lucano y Séneca autorizan esa interpretación, por lo que este Mercurio sería equivalente a Caelestis o Divinus. ${ }^{87}$ De acuerdo con la taxonomía de los epítetos, Supernus es pues un epíteto topográfico referido a una realidad intangible, la celestial morada de los dioses, aunque también cabría la posibilidad de considerarlo como expresión de una cualidad intrínseca de la divinidad con deseo manifiesto de exaltación.

\section{Conclusiones}

A tenor de la información recuperada podemos afirmar que el uso de epítetos o secuencias onomásticas no permite establecer comportamientos en el ámbito rural diferentes de la ortopraxis religiosa propia del ámbito urbano. En efecto, hemos constatado la acción de magistrados en espacios rurales, el empleo de las mismas categorías de epítetos en el campo y en la ciudad de modo indiferenciado y la difusión del epíteto Augustus/a en el espacio rural, con frecuencia mayor en la provincia Bética que en las otras provincias hispanas. Ciertamente, hemos señalado algunos hechos singulares que pudieran ser expresión de manifestaciones religiosas específicamente rurales, que no rústicas. Incluso, podríamos exhibir algún ejemplo susceptible de ser analizado desde la perspectiva de la lived religion, como el que se ha señalado de la Stata Mater. Sin embargo, esos casos singulares no son hechos diferenciales indicativos de una discontinuidad en la praxis religiosa entre el campo y la ciudad.

Esta conclusión coincide con las formuladas en este volumen con respecto a las realidades observadas en Lusitania y en Tarraconense. En consecuencia, todos los aspectos problemáticos planteados en la introducción de Alvar y Gasparini a este volumen han tenido cabal representación en la documentación analizada, lo que confirma la idea inicial de que no se debe hablar de religión rural. En definitiva, podríamos decir que el habitus ${ }^{88}$ religioso es común entre el ámbito rural y el urbano; hay un continuum entre estos dos espacios en los que se materializa la práctica

87. Ov., Met. XV 128; Luc., VI 430; Sen., Phaed. 926 y Nat. VI 8, 3. Mercurio aparece asociado a Caelestis en una inscripción de Roma (CIL VI 521 = EDCS-17300669).

88. Empleamos el término habitus en el sentido propuesto por Bourdieu, como entramado en el que se socializa el individuo: "a set of dispositions, durable and transposable systems of schemata of perception, appreciation and actions that result from the institution of the social in the body, and fields" (Bourdieu, 1990, p. 53). En consecuencia, el habitus emerge de las formas colectivizadas de ser, pensar, sentir o actuar, que, a su vez, se ven ahormadas por el habitus, como predisposición del comportamiento individual. Cf. Maton, 2008, pp. 49-66. Sobre el habitus en la religión antigua ahora es imprescindible consultar el volumen monográfico de Arys 18 (2020), Rituals and Habitus in the Ancient World: Begemann et al., 2020. 
religiosa. El campo de experimentación puede accionar determinados recursos específicos en uno u otro espacio, pero en la medida en la que se ha podido analizar, ninguna de las acciones singulares estudiadas establece una realidad diferencial que justifique una ruptura del habitus en el territorio provincial de la Bética. 


\section{IMÁGENES}

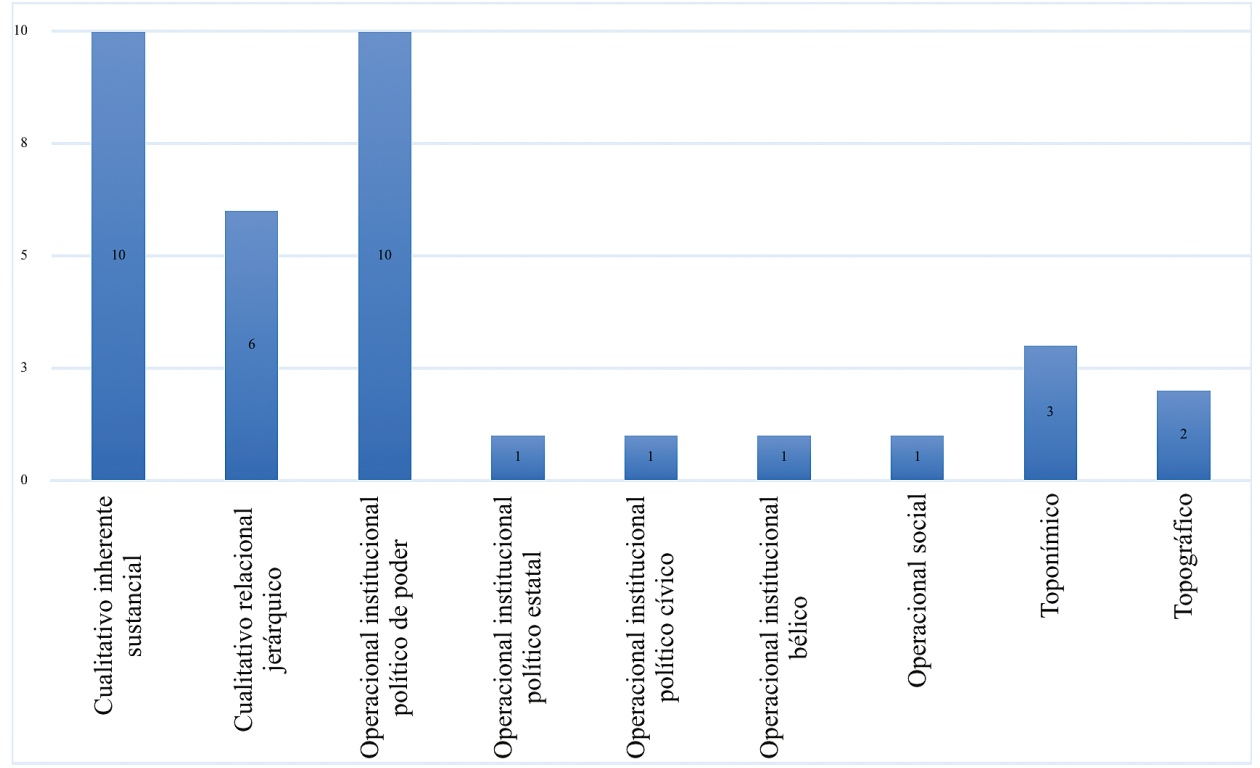

Fig. 1: Categorías de epítetos documentados en zonas rurales de la Bética.

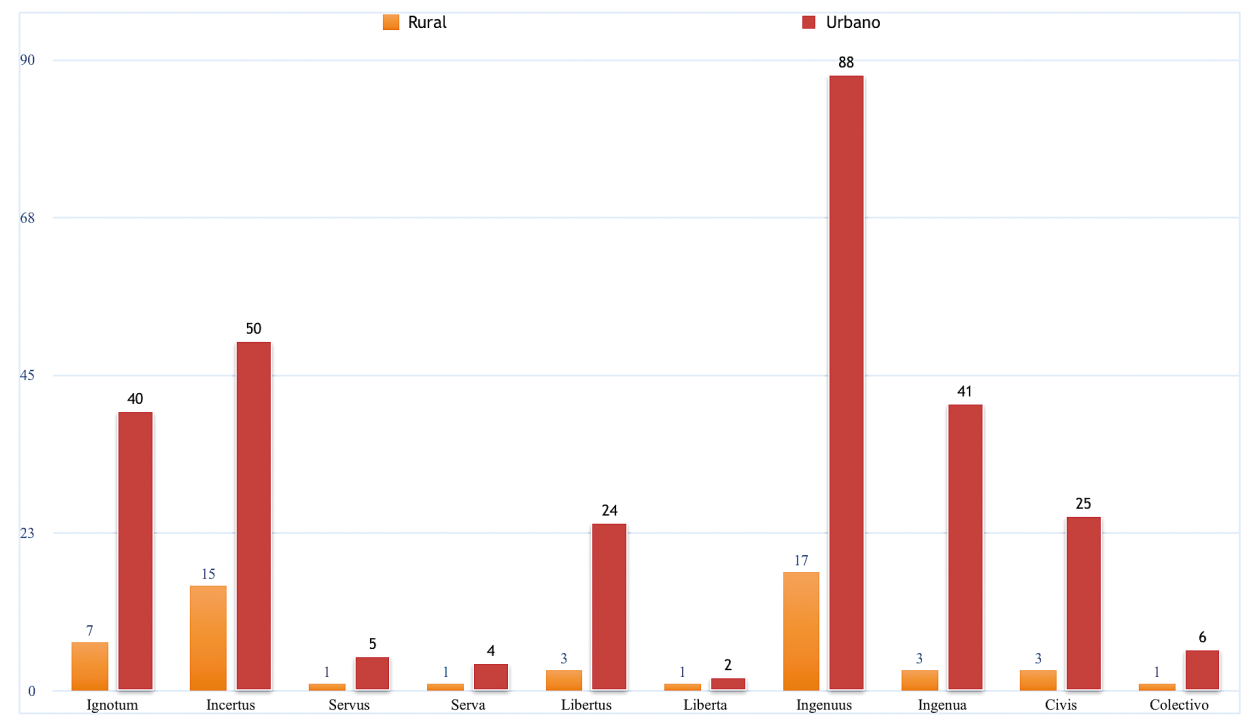

Fig. 2: Estatus socio-jurídicos de los dedicantes de la Bética. 


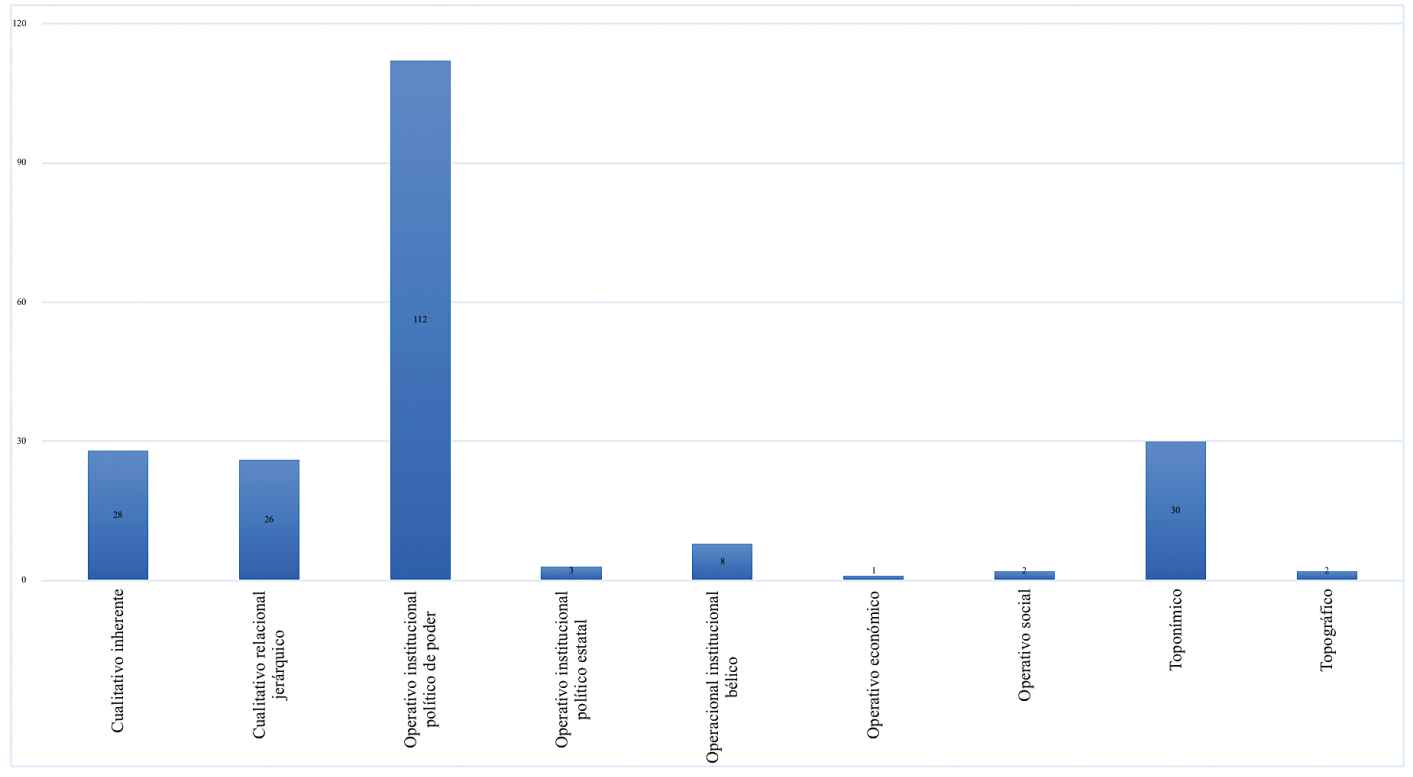

Fig. 3: Categorías de epítetos documentados en zonas urbanas de la Bética. 


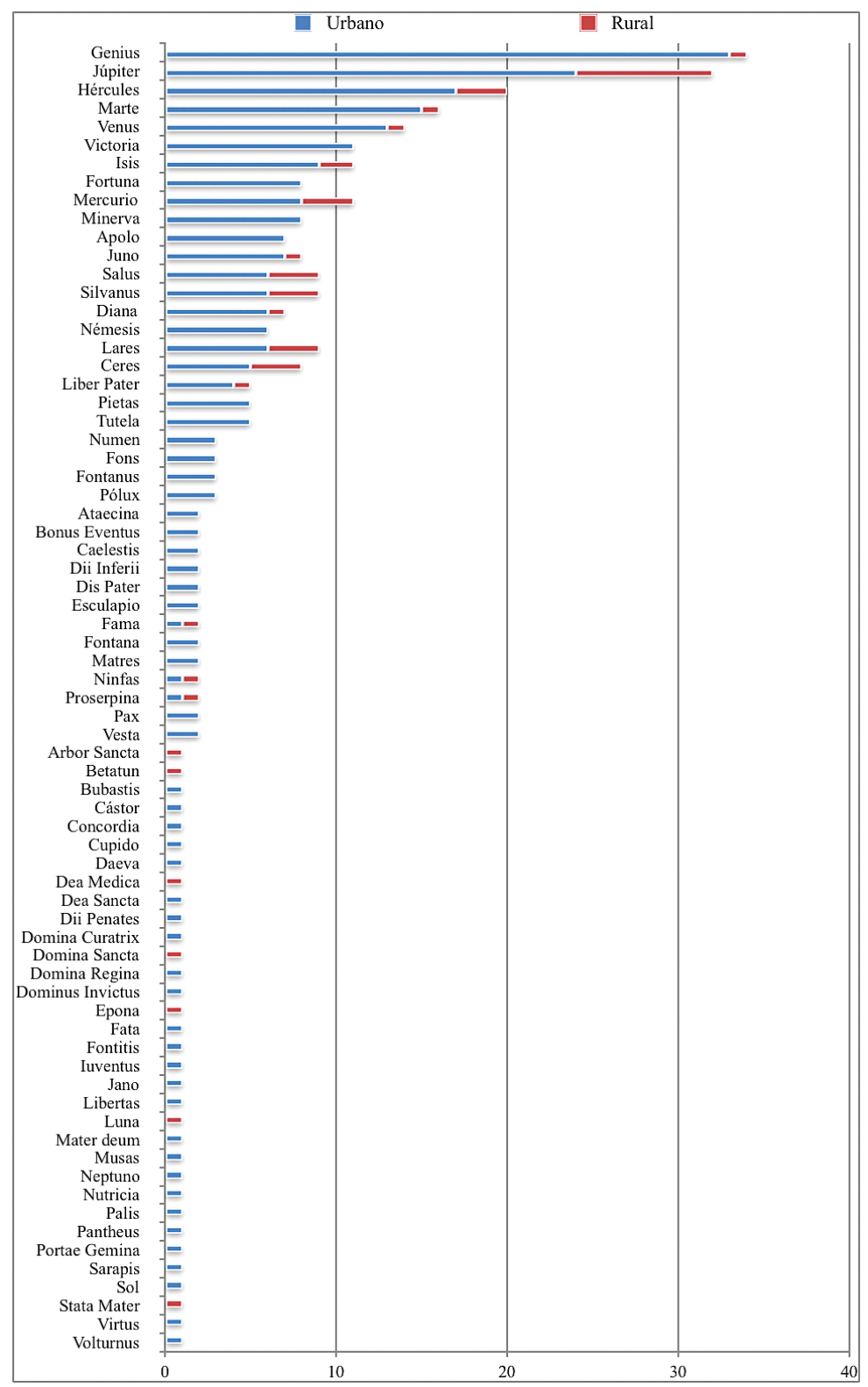

Fig. 4: Dioses documentados en la Bética urbana y rural. 


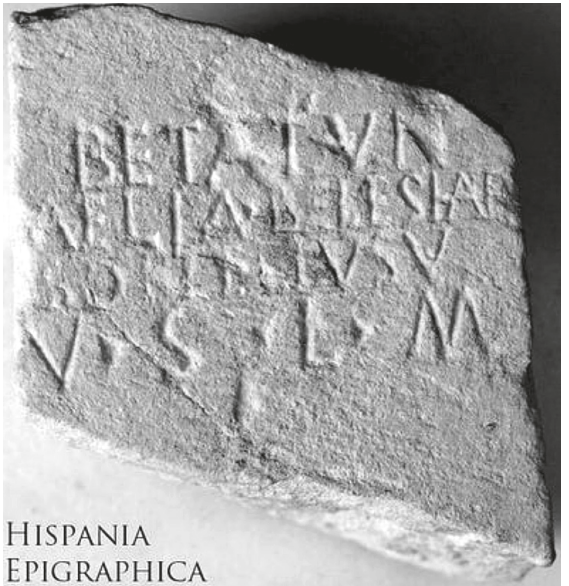

Fig. 5: Dedicación a Betatun (Fuente: HEPOL 25969).

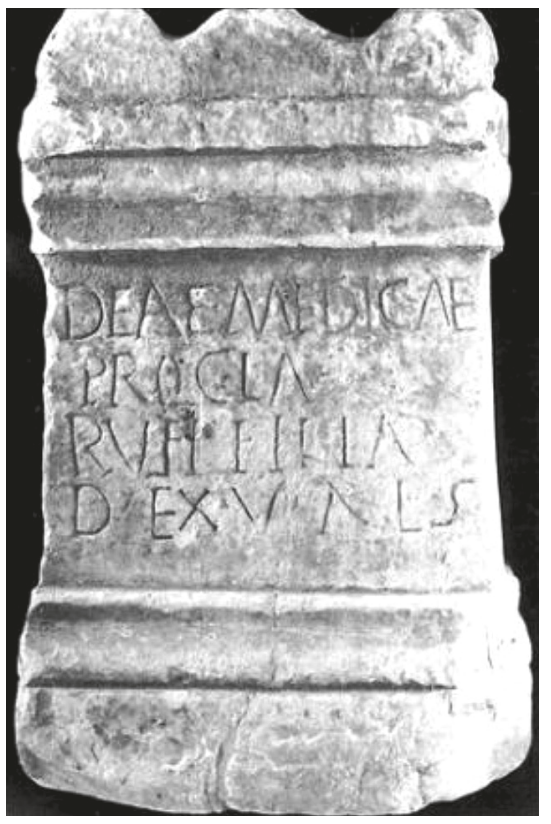

Fig. 6: Altar dedicado a Dea Medica. Museu Regional de Évora

(Fuente: HEpOL 5219). 

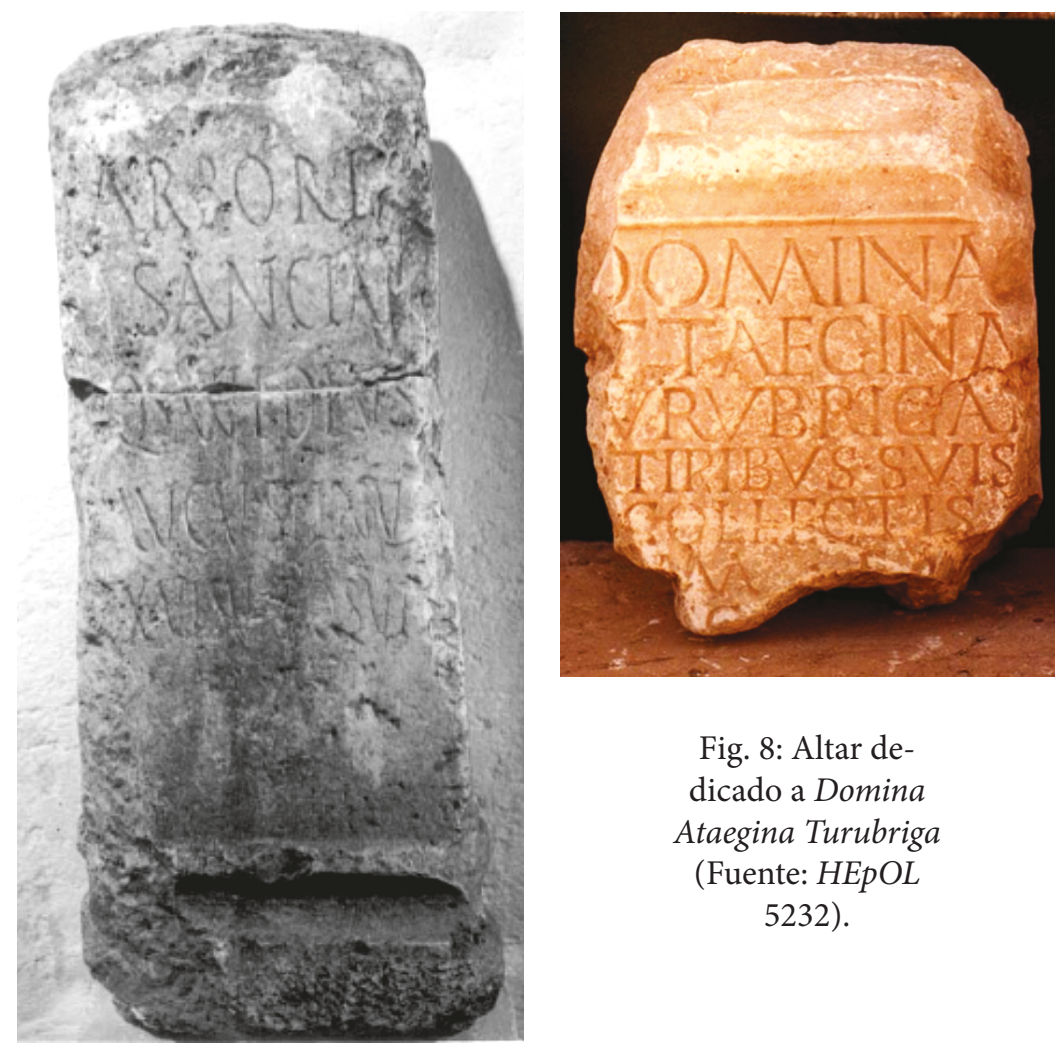

Fig. 8: Altar dedicado a Domina Ataegina Turubriga (Fuente: $H E p O L$ 5232).

Fig. 7: Altar dedicado al Arbor Sancta (Fuente: $H E p O L$ 3353). 


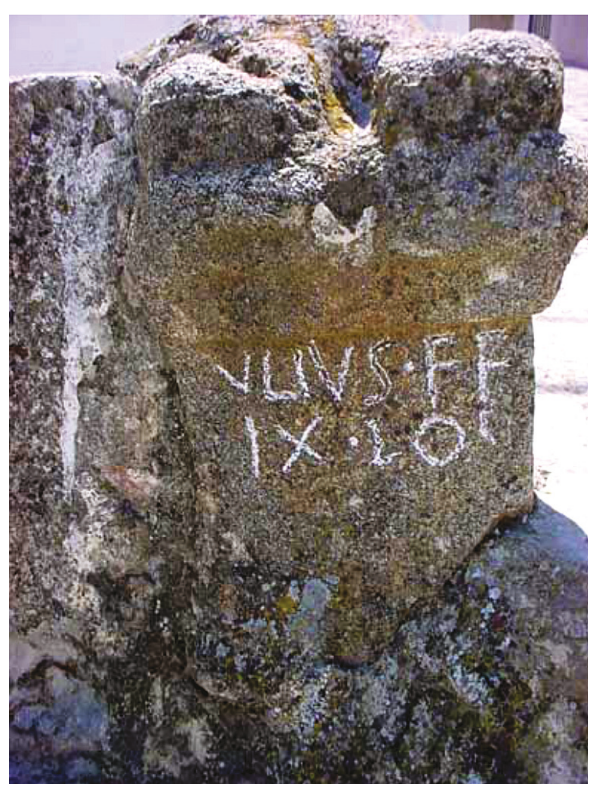

Fig. 9: Altar dedicado a Do(mina) S(ancta) (?) (Fuente: HEpOL 735).

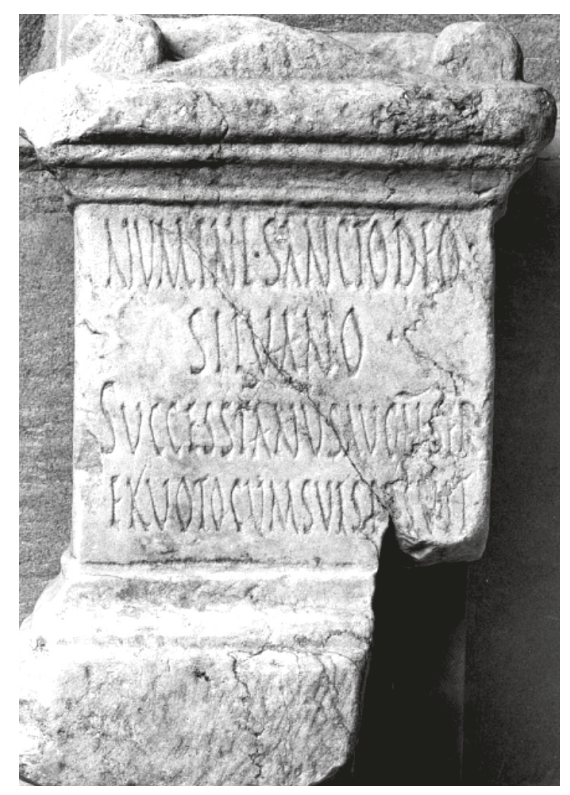

Fig. 10: Altar dedicado a Numen Sanctus Deus Silvanus

(Fuente: HEPOL 3706). 


\section{Abreviaturas}

RICIS = Bricault, Laurent (2005). Recueil des inscriptions concernant les cultes isiaques (RICIS).

3 vols. Paris: De Boccard.

SIRIS = Vidman, Ladislav (1969). Sylloge inscriptionum religionis Isiacae et Sarapiacae (SIRIS).

Religionsgeschichtliche Versuche und Vorarbeiten 28. Berlin y Nueva York: De Gruyter.

\section{Bibliografía}

Abascal Palazón, Juan Manuel (2019). Geografía de los altares de tres foculi dedicados a Lares Viales en Hispania. Anales de Arqueología Cordobesa, 30, pp. 257-280.

Acuña Castroviejo, Fernando (1971). Los Lares Viales en la Galicia romana. En De Alarcão, 1971, pp. 353-357.

Adroher Auroux, Andrés María, López Marcos, Antonio y Pachón Romero, Juan Antonio (2002). La cultura ibérica. Granada arqueológica. Granada: Diputación de Granada.

Alarcão, Jorge, Étienne, Robert y Fabre, Georges (1969). Le culte des Lares à Conimbriga. Comptes rendus des séances de l'Académie des inscriptions et belles-lettres, pp. 213-236.

Alvar Ezquerra, Jaime (2012). Los cultos egipcios en Hispania. Besançon: Presses Universitaires de Franche-Comté.

Alvar Ezquerra, Jaime (e.p.). El panteón de Itálica y sus epítetos. Archivo español de arte y arqueología, e.p.

Andreu Pintado, Javier (2017). La sacralización del agua en Hispania romana: una perspectiva epigráfica. En Pérex Agorreta y Miró i Alaix, 2017, pp. 84-114.

Athanassiadi, Polymnia y Frede, Michael (eds.) (1999). Pagan Monotheism in Late Antiquity. Oxford: Clarendon Press.

Begemann, Elisabeth, Rieger, Anna-Katharina, Rüpke, Jörg, Spickermann, Wolfgang y Waldner, Katharina (eds.) (2020). Rituals and Habitus in the Ancient World. Arys 18. Madrid: Dykinson.

Belayche, Nicole (2010). Hypsistos. Une voie de l'exaltation des dieux dans le polythéisme gréco- romain. $A R G, 7.1, \mathrm{pp} .34-55$.

Belayche, Nicole (2011). Hypsistos: A Way of Exalting the Gods in Graeco-Roman Polytheism. En North y Price, 2011, pp. 139-174.

Belayche, Nicole (2020). Kyrios and Despotes: Addresses to Deities and Religious Experiences. En Gasparini et al., pp. 87-115.

Beltrán Fortes, José (1982-1983). Una dedicación a los Lares Viales en la Bética. Mainake, 4-5, pp. 237-242.

Beltrán Fortes, José y Atencia, Rafael (1996). Nuevos aspectos del culto isiaco en la Baetica. SPAL, 5, pp. 171-196.

Beltrán Fortes, José y Mercado Hervás, Laura (2010). Pelagia en Hispalis (Sevilla). En Fornis et al., 2010, II, pp. 1129-1141. 
Beltrán Lloris, Francisco (1993). Culto a los lares y grupos de parentesco en la Hispania indoeuropea. En Mayer y Gómez Pallarè, 1993, pp. 59-72.

Bermejo Barrera, José Carlos (1986). Mitología y mitos de la Hispania prerromana. 2 vols. Madrid: Akal.

Blanco Freijeiro, Antonio (1968). Documentos metróacos de Hispania. Archivo español de arte y arqueología, 41, pp. 91-100.

Bourdieu, Pierre (1990). The Logic of Practice. Stanford: Stanford University Press.

Cadotte, Alain (2002). Pantheus et Dii deaeque omnes: les formules de synthèses divines en Afrique du Nord. Antiquités Africaines, 38-39, pp. 55-72.

Canto Montemolín, Alicia Ma . (1997). Epigrafía romana de la Beturia céltica. Madrid: Universidad Autónoma de Madrid.

Cardim Ribeiro, José y Alves Fernandes, Carla (2002). Ara consagrada a Venus, por Iulius Rufinus, magister. En Raposo, 2002, nº 97.

Chaparro Gómez, César (ed.) (1986). Primeras Jornadas sobre manifestaciones religiosas de la Lusitania. Cáceres: Universidad de Extremadura.

Corell, Josep (1999) Inscripcions romanes d'Ilici, Lucentum, Allon, Dianium, i els seus respectius territoris. Valencia: Nau Llibres.

Corzo Pérez, Sebastian, Pastor Muñoz, Mauricio, Stylow, Armin U. y Untermann, Jürgen. (2007). Betatun, la primera divinidad ibérica identificada. Palaeohispanica, 7, pp. 251262.

Covello, Vincent T. y Mumpower, Jeryl (1985). Risk Analysis and Risk Management: An Historical Perspective. Risk Analysis. An International Journal, 5.2, 103-120

Covello, Vincent T. et al. (eds.) (1986). Risk Evaluation and Management. Nueva York: Plenum Press.

Dardaine, Sylvie, Fincker, Miriam, Lancha, Janine, Sillières, Pierre. (2008). Belo VIII. Le sanctuaire d'Isis. Madrid: Casa de Velázquez.

De Alarcão, Jorge (ed.) (1971). Actas do II Congresso Nacional de Arqueología (Coimbra 1970). 2 vols. Coimbra: Imprenta Nacional.

Diosono, Francesca (2006). Note sull" "Arbor Sancta” a "Urso" e Roma. Habis, 37, pp. 387-398. Dorcey, Peter F. (1992). The Cult of Silvanus. A Study in Roman Folk Religion. Leiden: Brill.

Douglas, Mary (2003). Risk Acceptability According to the Social Sciences. Londres: Routledge ( $1^{\circ}$ ed. 1986).

Douglas, Mary y Wildavsky, Aaron (1982). Risk and Culture. An Essay on the Selection of Technological and Environmental Dangers. Berkeley: University of California Press.

Esteban Ortega, Julio (1984). Epígrafe sobre la diosa Ataecina en Bienvenida (Badajoz). En Actas de las II Jornadas de Metodología y Didáctica de la Historia (Historia Antigua). Cáceres: Universidad de Extremadura, pp. 21-25.

Fernández Fuster, Luis (1950). La fórmula ex visu en la epigrafía hispánica. Archivo español de arte y arqueología, 80, pp. 279-291. 
Fornis, César, Gallego, Julián, López Barja, Pedro y Valdés, Miriam (eds.) (2010). Dialéctica histórica y compromiso social. Homenaje a Domingo Plácido. 2 vols. Zaragoza: Libros Pórtico.

García, José Manuel (1991). Religiões antigas de Portugal. Aditamentos e observações às Religiões da Lusitânia de J. Leite de Vasconcelos: fontes epigráficas. Lisboa: Imprensa Nacional-Casa da Moeda.

García y Bellido, Antonio. (1967). Les religions orientales dans l'Espagne Romaine. EPRO 5. Leiden: Brill.

Gasparini, Valentino (ed.) (2016). Vestigia Miscellanea di studi storico-religiosi in onore di Filippo Coarelli nel suo $80^{\circ}$ anniversario. Potsdamer Altertumswissenschaftliche Beiträge 55. Stuttgart: Franz Steiner.

Gasparini, Valentino, Patzelt, Maik, Raja, Rubina, Rüpke, Jörg y Urcioli, Emiliano R. (eds.) (2020). Lived Religion in the Ancient Mediterranean World, Approaching Religious Transformations from Archaeology, History and Classics. Berlin: De Gruyter.

Gil Mantas, Vasco (2010). Os Lares Viales na Lusitânia. Vialibus - Revista de Cultura, 2, pp. 13-34.

Gómez Vila, Javier (2004). Dedicatorias a los Lares Viales en la provincia de Lugo. Gallaecia, 23, pp. 135-154.

Gimeno, Helena y Velaza, Javier (2021). Salagin: un nuevo teónimo en una inscripción de Riotinto (Huelva). Epigraphica, 83, pp. 201-208.

González Fernández, Enrique y Rodríguez Colmenero, Antonio (2002). Dos hallazgos singulares en las recientes excavaciones de Lugo: un edículo sacro y un alfabeto latino de época romana. Larouco, 3, pp. 243-251.

González Román, Cristóbal (ed.) (1991). La Bética en su problemática histórica. Granada: Universidad de Granada.

Grenfell, Michael (ed.) (2008). Pierre Bourdieu - Key concepts (49-66). Londres: Acumen.

Grier, Bill (1981). The Early History of the Theory and Management of Risk. Philadelphia, pp. $1-13$.

Heinzmann, Manfred (ed.) (2007). Auf den Spuren keltischer Götterverehrung. Akten des 5. F.E.R.C.A.N. - Workshop, Graz 9.-12. Oktober 2003. Viena: Manfred Hainzmann.

Hernando Sobrino, María del Rosario (2003). Mercurius Supernus en un epígrafe inédito de la provincia de Badajoz. Ficheiro Epigráfico, 71, pp. 10-16.

Lambrino, Scarlat (1965). Les cultes indigènes en Espagne sous Trajan et Hadrien. En Piganiol, Terrasse y Etienne, 1965, pp. 223-242.

López Melero, Raquel (1986). Nueva evidencia sobre el culto de Ategina: El epígrafe de Bienvenida. En Chaparro Gómez, 1986, pp. 93-112.

Lott, John Bert (2004). The Neighborhoods of Augustan Rome. Nueva York: Cambridge University Press.

Malaise, Michel (1972). Les conditions de pénétration et de diffusion des cultees égyptiens en Italie. EPRO 22. Leiden: Brill. 
Mangas Manjarrés, Julio (1983). La difusión de la religión romana en Asturias. En Maya González, 1983, pp. 167-177.

Mangas Manjarrés, Julio (1991). Pantheus en Hispania. En González Román, 1991, pp. 111132.

Marco Simón, Francisco (2007a). Within the Confines of the Romano-Celtic World. The Gods of the Roads. En Heinzmann, 2007, pp. 197-205.

Marco Simón, Francisco (2007b). La novedad en la memoria: el dios Betatun y un ritual de plegaria familiar en el santuario ibérico de Las Atalayuelas (Fuerte del Rey, Jaén). En Vallejo, Igartua Ugarte y García Castillero, 2007, pp. 301-312.

Maton, Karl (2008). Habitus. En Grenfell, 2008, pp. 49-66.

Maya González, José Luis (ed.) (1983). Indigenismo y romanización en el Conventus Asturum. Oviedo: Universidad de Oviedo.

Mayer, Marc y Gómez Pallarès, Joan (eds.) (1993). Religio deorum: actas del coloquio internacional de epigrafía "Culto y sociedad en Occidente". Tarragona: AUSA.

Mitchell, Stephen (1999). The Cult of Theos Hypsistos between Pagans, Jews and Christians. En Athanassiadi y Frede, 1999, pp. 81-148.

Mora, Fabio (1990). Prosopografia Isiaca. 2 vols. EPRO 113. Leiden: Brill.

Muñiz Grijalvo, Elena (2019). Adriano y la religión egipcia. Perspectivas pasadas y presentes. En Romero Recio, 2019, pp. 81-95.

North, John A. y Price, Simon R.F. (eds.) (2011). The Religious History of the Roman Empire. Pagans, Jews and Christians. Oxford: Oxford University Press.

Orduña Aznar, Eduardo (2009). Nueva interpretación de la inscripción de 'Betatun'. Veleia, 26, pp. 359-362.

Ortiz Ayala, Cayetano (1988). El culto de Cibeles en la Hispania romana. En Pereira Menaut, 1988, pp. 441-453.

Palazzo, Paola y Pavolini, Carlo (eds.) (2013). Gli dèi propizi. La basilica Hilariana nel contesto dello scavo dell'Ospedale Militare Celio (1987-2000). Roma: Quasar.

Parker, Robert (2017). Greek Gods Abroad: Names, Natures, and Transformations. Sather Classical Lectures 72. Oakland: University of California Press.

Pastor Muñoz, Mauricio (1987-1988). La diosa romana Stata Mater en Iliberris. Unico testimonio epigráfico en Hispania. Cuadernos de Prehistoria y Arqueología de la Universidad de Granada, 12-13, pp. 237-250.

Pastor Muñoz, Mauricio (2002). Corpus de inscripciones latinas de Andalucía. CILA IV. Sevilla: Consejería de Cultura de la Junta de Andalucía.

Pastor Muñoz, Mauricio y Mendoza Eguaras, Ángela (1987). Inscripciones latinas de la provincia de Granada. Granada: Universidad de Granada.

Pavolini, Carlo (2016). Ancora sui culti orientali a Roma. Dagli hymnologi di Cibele alle nuove ipotesi topografiche. En Gasparini, 2016, pp. 337-348..

Pereira Menaut, Gerardo (ed.) (1988). Actas 1er. Congreso Peninsular de Historia Antigua. Santiago de Compostela: Universidad de Santiago de Compostela. 
Pérex Agorreta, María Jesús y Miró i Alaix, Carme (eds.) (2017). VBI AQVAE IBI SALVS. Aguas mineromedicinales, termas curativas y culto a las aguas en la Península Ibérica (desde la Protohistoria a la Tardoantigüedad). Madrid: Universidad Nacional de Educación a Distancia.

Phillips, C. Robert (2006) Stata Mater. En Brill's New Pauly, https://referenceworks.brillonline.com/entries/brill-s-new-pauly/*-e1121110.

Piganiol, André, Terrasse, Henri y Etienne, Robert (eds.) (1965). Les empereurs romains d'Espagne. París: CNRS.

Prósper Pérez, Blanca María (2002). Lenguas y religiones prerromanas del occidente de la Península Ibérica. Salamanca: Universidad de Salamanca.

Raposo, Luis (ed.) (2002). Religioes da Lusitania. Loquuntur saxa. Catálogo de la exposición. Lisboa: MNA.

Renberg, Gil H. (2017). Where Dreams May Come: Incubation Sanctuaries in the Greco-Roman World. RGRW 187. Leiden y Boston: Brill.

Richardson, Lawrence Jr. (1992). A New Topographical Dictionary of Ancient Rome. Johns Hopkins University Press.

Romero Recio, Mirella (ed.) (2019). El legado de los emperadores hispanos. Sevilla: Universidad de Sevilla.

Santos Yanguas, Narciso (2012). El culto a los Lares Viales en Asturias. Ilu. Revista de Ciencias de las Religiones, 17, 173-184.

Serrano Ordozgoiti, David (2018). Ara de mármol en honor del Arbor Sancta proveniente de Osuna (Sevilla). Boletín del Archivo Epigráfico, 2, pp. 26-30.

Sotomayor Muro, Manuel (1996). Casería Titos (Granada). Noticiario Arqueológico Hispánico, 8-9, Cuadernos 1-3, p. 354.

Uroz Rodríguez, Héctor (2012). Prácticas rituales, iconografía vascular y cultura material en Libisosa (Lezuza, Albacete). Nuevas aportaciones al Ibérico Final del Sudeste. Alicante: Universidad de Alicante - Cajasol Obra Social.

Vallejo, José María, Igartua Ugarte, Iván y García Castillero, Carlos (eds.) (2007). Studia Philologica et Diachronica in Honorem Joaquín Gorrochategui. Indoeuropaea et Palaeohispanica. Anejos Veleia Series Minor 35. Vitoria: Universidad del País Vasco.

Villaret, Alain (2019). Les dieuxaugustes dansl'Occident romain. Un phénomène d'acculturation. Burdeos: Ausonius. 